Article

\title{
A Coordinated Dispatching Model Considering Generation and Operation Reserve in Wind Power-Photovoltaic-Pumped Storage System
}

\author{
Dai Cui ${ }^{1,2}$, Fei $\mathrm{Xu}^{3, *}$, Weichun Ge ${ }^{1,2}$, Pengxiang Huang ${ }^{4, *}$ and Yunhai Zhou ${ }^{4}$ \\ 1 School of Electrical Engineering, Shenyang University of Technology, Shenyang 100084, China; \\ cuidai1982@sut.edu.cn (D.C.); geweichun1961@sut.edu.cn (W.G.) \\ 2 State Grid Liaoning Electric Power Co., Ltd., Shenyang 100084, China \\ 3 Department of Electrical Engineering, Tsinghua University, Beijing 100084, China \\ 4 College of Electrical Engineering \& New Energy, China Three Gorges University, Yichang 443000, China; \\ zhouyunhai@ctgu.edu.cn \\ * Correspondence: xufei@tsinghua.edu.cn (F.X.); 201808520721031@ctgu.edu.cn (P.H.); \\ Tel.: +86-1351-100-3897 (F.X.); +86-1843-436-1831 (P.H.)
}

Received: 18 August 2020; Accepted: 14 September 2020; Published: 16 September 2020

check for updates

\begin{abstract}
Large-scale grid integration of renewable energy increases the uncertainty and volatility of power systems, which brings difficulties to output planning and reserve decision-making of power system units. In this paper, we innovatively combined the non-parametric kernel density estimation method and scenario method to describe the uncertainty of renewable energy outputs, and obtained a representative set of renewable energy output scenarios. In addition, we proposed a new method to determine the reserve capacity demand. Further, we derived the quantitative relationship between the reserve demand and the power system reliability index, which was used as the constraint condition of a day-ahead power generation dispatch. Finally, a coordinated dispatching model of power generation and reserve was established, which had the lowest penalty for curtailment of wind power and photovoltaic, as well as the lowest total operating cost for thermal power units, gas power units, and pumped storage power station. By simulating three different working conditions, the proposed model was compared with the traditional deterministic model. Results showed that our proposed method significantly improved system efficiency while maintaining system reliability.
\end{abstract}

Keywords: pumped storage; renewable energy; operation reserve; non-parametric kernel density estimation; scenario method; coordinated dispatching

\section{Introduction}

In recent years, wind power (WP) and photovoltaic (PV) have achieved sustained and rapid development. However, the output of WP and PV is very unstable. Large-scale WP and PV are connected to the grid and the generation side uncertainty of the power system is aggravated [1-3]. In Europe, balancing the power grid is mainly realized by using gas-based power generation units and pumped storage power station (PSPS), but natural gas is imported, and the geographical location of pump storage units is greatly restricted, which brings great difficulties to power grid balancing [4]. The increasing share of intermittent renewable energy generation and changing patterns of electricity demand pose challenges not only to the balance of the grid but also to the security of the supply. In China, there are many studies on renewable energy and energy storage complementary power generation technologies, but chemical energy storage systems, such as batteries, are generally preferred. The battery has its own disadvantage that cannot be changed. The service life of the battery is affected by frequent charge and discharge, which reduces the system economy. The discarded batteries may 
cause environmental pollution in the recovery process. The technology of PSPS in China is relatively mature. The participation of PSPSs in dispatching can improve the flexibility of the power system and effectively solve the problem of power grid balancing [5].

Aiming at the complementary power generation technology of the new energy system and energy storage system, the present research mainly focuses on the optimization operation of the joint system. Reference [6] established a wind-photovoltaic-pumped storage complementary power generation system under the condition of an isolated network operation, which compared and analyzed the operation status of PSPSs with different capacities, and determined an optimal determination method of pumped storage capacity. Reference [7] studied the problem of wind-photovoltaic-pumped storage system's uncertain unit commitment, based on the parameter estimation method to obtain wind-solar output interval, using scene method to describe the uncertainty of wind-photovoltaic output, proposed the binary artificial sheep algorithm (BASA) algorithm to solve it, and verified the validity of the model. Reference [8] focused on the optimal day-ahead scheduling of hybrid power systems, including WP, PV, cascade hydropower, thermal power units, and PSPS. Taking into account the complementary characteristics of these power sources, a day-ahead joint optimal scheduling model for multi-source power systems with the goal of maximizing safety and economy was established. Reference [9] proposed an optimal dispatch model for the WP-PV energy storage system, aiming at the frequency stability of the power grid. The optimal control strategy was proposed to reduce the dependence on the energy storage system, reduce equipment operation and maintenance costs, and improve the reliability of the power system. Reference [10] proposed different control strategies for distributed energy storage (DES) and established a unit commitment model considering inertia constraints, dynamic reserve allocation, and interconnection flexibility. However, the prediction error of PV and WP in this paper was assumed to be normally distributed. The "3-sigma" rule was adopted for PV reserve demand calculation and the "3.5-sigma" rule was adopted for WP reserve demand calculation. Reference [11] put forward the difference between uncertainty and variable reserves, captured the dual nature of renewable energy power generation, and established a multi-time-scale random unit commitment model without a quantitative analysis of the reserve demand or a detailed description of the influence of energy storage in scheduling. However, the authors did not make a quantitative analysis of the reserve demand, nor did they give a detailed description of the impact of energy storage in scheduling. In reference [12], a probabilistic microgrid scheduling problem was considered and a hybrid approach combining scene selection optimization and reserve strategy using model predictive control (MPC) framework was proposed. In reference [13], a framework for quantitative analysis of any energy storage system was proposed for reliability and flexibility in power systems. The authors used a genetic algorithm to solve the combined dispatching of WP and pumped storage power plants. Reference [14] mainly studied the frequency regulation control architecture of renewable hybrid power plants, including WP, PV, and battery energy storage systems. The results showed that the hybrid power generation system had good frequency regulation ability, stabilized the frequency of the system in a very short time, and improved the reliability of the power system.

The power system needs to be equipped with a sufficient reserve capacity to ensure stable, safe, and continuous power supply. Operation reserve refers to the capacity reserved for quick active power response in order to cope with fluctuations in load and renewable energy output, generator outage, etc., to meet the requirements of reliable and continuous power supply for a load [15]. The large-scale connection of renewable energy into the grid has brought more uncertainty to the power system and increased the operation reserve demand capacity. Too little reserve capacity configuration leads to system security and reliability reduction; too much configuration improves system reliability, but it compresses units power generation space and causes uneconomical phenomena [16]. Understanding how to configure the appropriate reserve capacity to ensure the reliability of the power system is very necessary.

The traditional power system reserve decision-making plan is based on a deterministic model. The power system reserve demand per hour of the system is usually determined by the maximum unit 
capacity or the load percentage. This method does not consider the quantitative relationship between unit output and reserve decision, and the result makes it difficult to achieve global optimization [17]. With the large-scale integration of renewable energy such as WP to the power grid, the traditional reserve decision-making methods have been difficult to apply to the power system. In order to reduce the uncertainty caused by renewable energy, some scholars proposed a coordinated dispatch model for power generation and reserve, which described the unit output and reserve decision jointly as an optimization problem with constraints, and obtained the optimal solution while satisfying the reliability constraints. Reference [18] proposed an index of expected load not supplied ratio to quantify the minimum allowable load shedding per hour and derived the quantitative relationship between this indicator and the operation reserve. However, it failed to consider the uncertainty of WP and reserve cost, so it could not meet economic requirements. Reference [19] analyzed the distribution of wind resources and studied the impact of WP grid connection and its prediction errors on power system dispatching. However, in terms of reserve decision-making, a deterministic method was adopted. The unit output and reserve decision were scheduled in sequence, without taking into account the influence of WP volatility on reserve demand; the overly simple constraint conditions made the results unrepresentative. In reference [20], a spinning reserve acquisition model was constructed based on the opportunistic constraint programming method. However, the Monte Carlo stochastic simulation may have led to long calculation time and less practicability, and the impact of positive and negative spinning reserve on the system after WP was connected to the grid was not considered. Reference [21] aimed to achieve the optimal configuration of spinning reserve with the goal of minimum the expected loss of load and the minimum unit operating cost. However, the reserve and unit output in this method were separately optimized, which made it difficult to ensure the optimal overall result. Reference [22] realized the coordination and optimization of unit output and spinning reserve under the condition of high WP penetration, but it lacked the quantification between system reliability and reserve capacity.

In the research of renewable energy output models, there are two main types. One is to establish a deterministic model to obtain the specific value of renewable energy output. This method takes into account many factors, is difficult, and the result error is large, and thus it is challenging to provide a reliable basis for the power system. The other is to establish a probability distribution model to obtain the probability density function of a renewable energy output [23,24]. Compared with the deterministic model, the latter can better explain the uncertainty of renewable energy, with higher credibility and a wider range of applications. In establishing the probability distribution model of a renewable energy output, the parameter estimation method is generally adopted, assuming that the wind speed probability obeys the Weibull distribution and the light intensity probability obeys the Beta distribution. Then, the probability distribution functions of WP and PV output are obtained according to WP unit output function and PV panel output function $[25,26]$. The modeling process of this method is simple, but WP output and PV output are not only affected by wind speed and light intensity, so the results have large errors. The probability model established by the non-parametric estimation method does not require model assumptions about wind speed and light intensity, and only needs to estimate the probability model based on the historical data of renewable energy output, which can effectively reveal the statistical information hidden in the historical data and reduce the influence of uncertain factors on the probability model [27]. Reference [28] adopts the autoregressive moving average method with normal distribution of WP prediction error to model the wind speed time series and obtain the probability distribution of the WP output. Then, the Monte Carlo simulation was used to generate random samples of wind speed to generate WP output scenes. This method is inefficient and time-consuming, and requires a large number of samples to get good results. In reference [29], the authors successfully deduced the analytic expression of WP density function and the fourth-order statistics based on the historical data of the WP output, and extended the model of the WP output to a regional scale. References [30-32] adopted the non-parametric kernel density estimation method to calculate the probability density functions of different WP prediction errors. The obtained results had higher accuracy and better adaptability than the traditional wind 
speed parameter distribution method, and were applied to the field of reserve capacity demand determination and power generation scheduling.

The wind-photovoltaic-pumped storage system is mainly based on the wind farms and PV power stations, according to the local favorable terrain [33]. PSPS transfers and stores the unstable and fluctuating power supply that exist in wind farms and PV power stations during the generation process, and then converts it into stable power input. According to the characteristics of the WP output in northwest China, the wind speed at night is generally greater than that during the day [34]. Therefore, when the WP output increases, the excess energy can be stored in the PSPS. The pumping operation is performed by starting the water pump and then the excess electric energy of the wind farm is converted into the gravity potential energy of water for storage. In the same way, PV power stations convert energy through the same operation. When the grid load is high and the system power supply is difficult to balance the power demand, the PSPS generates power to release energy, which can reduce load shedding loss, improve the system's utilization of new energy, and reduce the impact of power fluctuation on the grid. The structure of wind power-photovoltaic-pumped storage system is shown in Figure 1.

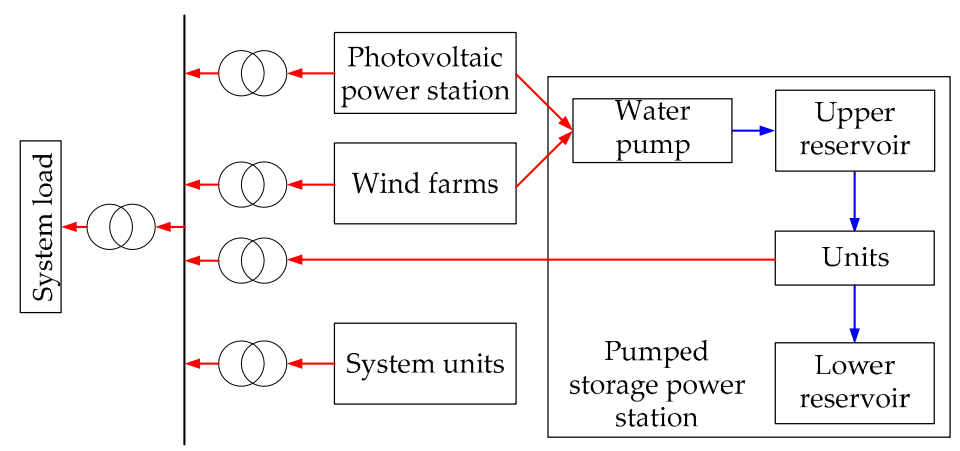

Figure 1. The structure of wind power-photovoltaic-pumped storage system.

In summary, many scholars have used the parameter estimation method to model the WP output and PV output. The modeling process of this method is simple, but the WP and PV outputs are not only affected by wind speed and light intensity, so the results obtained by using the parameter method have a large error. The traditional reserve decision scheme of the power system is based on the deterministic model. This method performs sequential scheduling of the unit output and reserve decisions, in turn, without considering the quantitative relationship between unit output and reserve decisions. As a result, it is difficult to achieve global optimal results and the traditional reserve decision method is difficult to apply to the power system. Aiming at the above problems, the main objectives and main innovations and contributions of this paper are as follows.

The primary aims of this paper, which are also its main novelty and contributions, are to: (a) consider that, under some special circumstances, the parameter estimation method for the prediction error of renewable energy output is invalid. Thus, this paper adopts the non-parameter kernel density estimation method to model the prediction error of the renewable energy output and obtain the probability distribution function of the prediction error of renewable energy output. (b) According to the probability distribution function obtained, the Latin hypercube sampling (LHS) method was used to sample the prediction error of renewable energy output, and a large number of renewable energy output scenes were obtained. A representative set of scenes were obtained by the simultaneous backward reduction (SBR) method. (c) A method for determining the operating reserve demand capacity based on the reliability index of power system is proposed and the quantitative relationship between the up-regulated operation reserve and the expected energy not supplied (EENS) per hour is derived. Moreover, the quantitative relationship between the down-regulated operation reserve and the expected WP and PV curtailed (EWPPC) per hour is derived. (d) A coordinated optimization model of power generation and standby is established, aiming at the minimum wind and light abandoning 
electricity quantity and the minimum total operating cost of thermal power units, gas units, and PSPSs. We optimized the reserve supply and optimal unit allocation scheme for each hour operation by coordinated dispatching. Finally, the validity of the proposed model is verified by comparing with the deterministic model.

The paper is structured as follows. In Section 2, the probability distribution model of renewable energy output ultra-short-term prediction error is mainly studied. In Section 3, the uncertainty of the WP and PV outputs are described by the scenario method. Based on the reliability index of the power system, the quantitative relationship between the hourly reserve demand and reliability index is derived in Section 4. The coordinated dispatching model considering generation and operating reserve is proposed in Section 5, and the case study is presented in Section 6. Finally, conclusions are drawn in Section 7.

\section{The Ultra-Short-Term Prediction Error Probability Distribution Model of the Wind and PV Output}

\subsection{The Non-Parametric Kernel Density Estimation Method}

Kernel density estimation is a type of non-parametric estimation, which can describe the continuous density function well. This method does not attach any assumptions to the data distribution and only studies the distribution characteristics of the data from its own characteristics [35]. In this paper, the non-parametric kernel density estimation method is used to obtain the ultra-short-term prediction error probability distribution functions of the WP output and PV output.

The historical data of the WP output prediction error and PV output prediction error are standardized, in which $P_{w}$ is the WP output prediction error data; $\left(P_{w 1}, P_{w 2}, \ldots, P_{w n}\right)$ is the sample space of WP prediction error data; $P_{p v}$ is the $\mathrm{PV}$ output prediction error data; $\left(P_{p v 1}, P_{p v 2}, \ldots, P_{p v n}\right)$ is the sample space of PV output prediction error data; $n$ is the sample size. Let the probability density function of random variable $x$ be $f(x)$, then the probability density function of the WP output prediction error is $f_{w}\left(P_{w}\right)$, and the probability density function of $\mathrm{PV}$ output prediction error is $f_{p v}\left(P_{p v}\right)$. Kernel density estimation was performed based on sample data $\left(P_{w 1}, P_{w 22}, \ldots, P_{w n}\right)$ and $\left(P_{p v 1}, P_{p v 2}, \ldots, P_{p v n}\right)$.

$$
f_{h}(x)=\frac{1}{n h} \sum_{i=1}^{n} K\left(\frac{x-x_{i}}{h}\right)=\frac{1}{n} \sum_{i=1}^{n} K\left(x-x_{i}\right)
$$

where $h$ is the bandwidth; $K(\cdot)$ is the kernel function, the most commonly used kernel functions are the Epanechikov function and Gaussian function. This paper chooses the Gaussian kernel function because $f_{h}(x)$ inherits the continuity and differentiability of the kernel function, so $f_{h}(x)$ is differentiable of any order.

$$
K(x)=\frac{1}{\sqrt{2 \pi}} \exp \left(-\frac{1}{2} x^{2}\right)
$$

If the bandwidth $h$ is too large, the deviation is too large and the variance too small, making $f_{h}(x)$ too smooth; if the bandwidth $h$ is too small, the deviation is too small and the variance increases, resulting in $f_{h}(x)$ under-smoothing. The bandwidth $h$ cannot reduce the deviation and variance at the same time, so the kernel density estimation should comprehensively weigh the deviation and the variance to find a suitable bandwidth [35].

In this paper, the empirical method is used to calculate the optimal bandwidth, so as to minimize the asymptotic mean integrated squared error (AMISE). When AMISE is the smallest, the bandwidth expression is:

$$
\begin{aligned}
& h=\left[\frac{R(K)}{n \mu_{2}^{2}(K) R\left(f^{\prime \prime}\right)}\right]^{1 / 5} \\
& R\left(f^{\prime \prime}\right)=\int\left(f^{\prime \prime}(x)\right)^{2} d x
\end{aligned}
$$


When selecting the kernel density estimation of the Gaussian kernel function, the normal reference criterion is used to simplify Equation (3) as:

$$
h=1.06 \sigma n^{-1 / 5}
$$

where $\sigma$ is the standard deviation of the sample variable. In this paper, a more robust Interquartile range $\left(I_{q r}\right)$ is considered to be adopted to replace the $\sigma$ in Equation (5) with Equation (6):

$$
\sigma_{I}=\min \left\{\sigma, \frac{I_{q r}}{\left(\Phi^{-1}(0.75)-\Phi^{-1}(0.25)\right)}\right\} \approx \min \left(\sigma, \frac{I_{q r}}{1.34}\right)
$$

where $\Phi$ is the standard normal cumulative distribution function. In order to achieve an accurate estimation of the probability density distribution, the coefficient is reduced to 0.9 , and the optimal bandwidth is obtained as follows:

$$
h=0.9 \min \left(\sigma, \frac{I_{q r}}{1.34}\right) n^{-1 / 5}
$$

\subsection{Prediction Error Probability Distribution of the Wind Power Output and PV Power Output}

The WP data used in this paper was the historical WP data for the island of Ireland [36]. The data used was the measured WP of 1 January 2014 solstice on 31 December 2014. There are 35,040 data in total and the time scale was $15 \mathrm{~min}$. The PV power data used was the historical PV power data of a domestic PV power station [37]. The data used was the measured PV power of 1 December 2017 solstice on 1 September 2018. There are 17,474 data in total and the time scale was $15 \mathrm{~min}$.

After processing, the prediction error kernel density estimation curves of the WP output and PV output were respectively obtained and compared with the frequency histogram of the actual data, as shown in Figure 2. It can be seen that the prediction error probability density curves of the WP output and PV output obtained by kernel density estimation were basically consistent with the frequency statistical graph of the actual data.

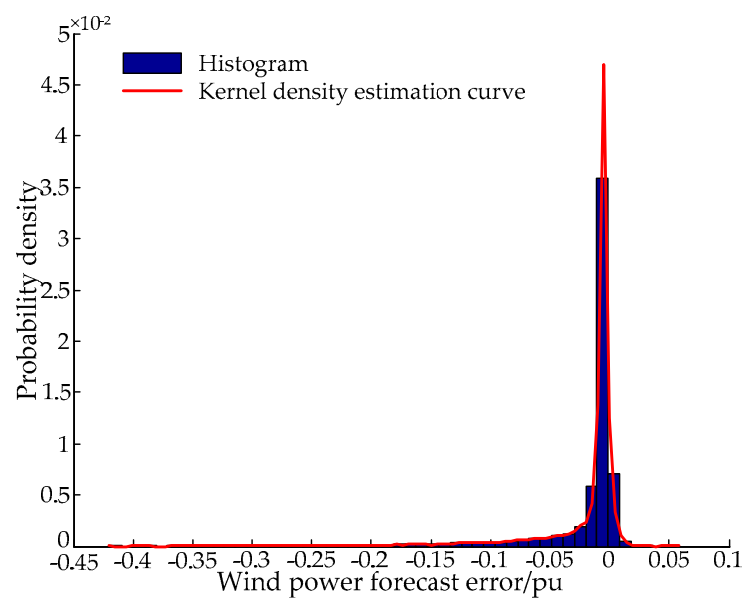

(a)

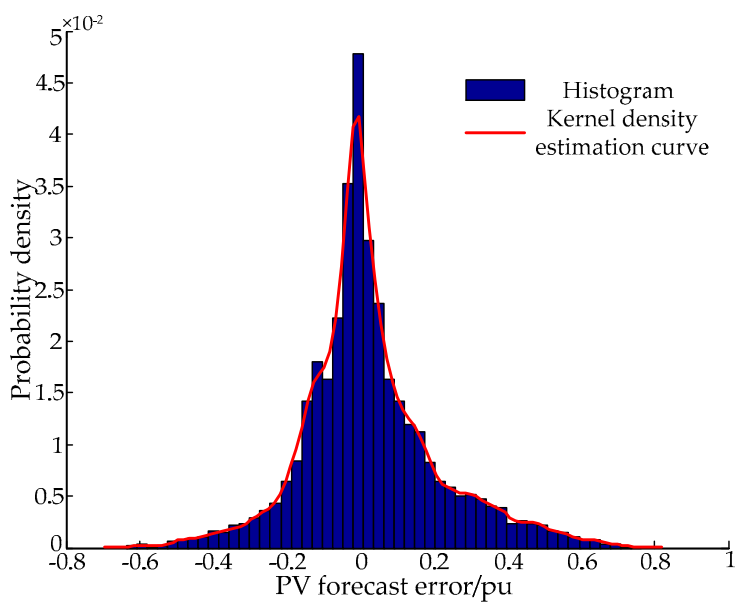

(b)

Figure 2. Fitting of probabilistic distribution of WP (a) and PV power prediction error (b).

We performed the following integral operation on the prediction error probability density function $f_{w}\left(P_{w}\right)$ of the WP output and the prediction error probability density function $f_{p v}\left(P_{p v}\right)$ of PV power output.

$$
F_{h}(x)=\int_{-\infty}^{x} f_{h}(x) d x
$$


where $f_{h}(x)$ is the prediction error probability density function of the WP output and PV power output; $F_{h}(x)$ is the prediction error cumulative probability distribution function of the WP output and PV power output.

After calculation, the cumulative probability distribution function $F_{w}\left(P_{w}\right)$ of the WP output prediction error and the cumulative probability distribution function $F_{p v}\left(P_{p v}\right)$ of the PV output prediction error are obtained, respectively, and the cumulative probability distribution curve is shown in Figure 3.

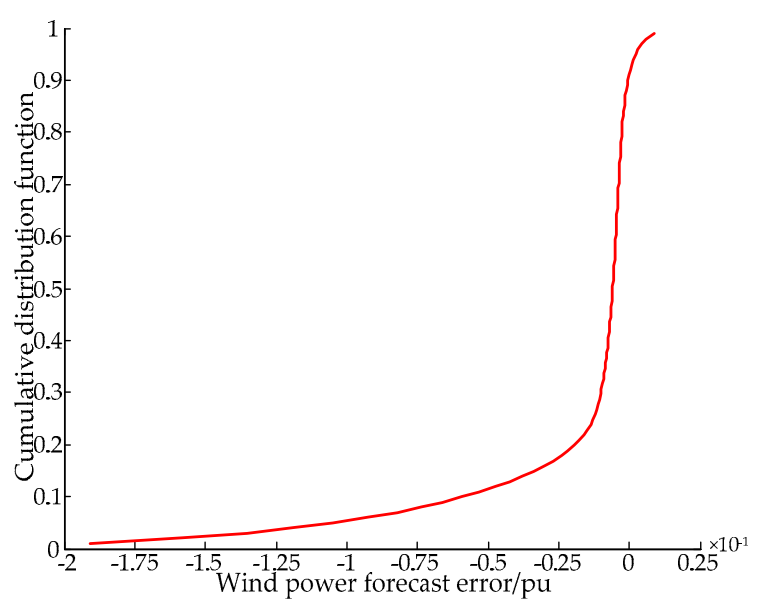

(a)

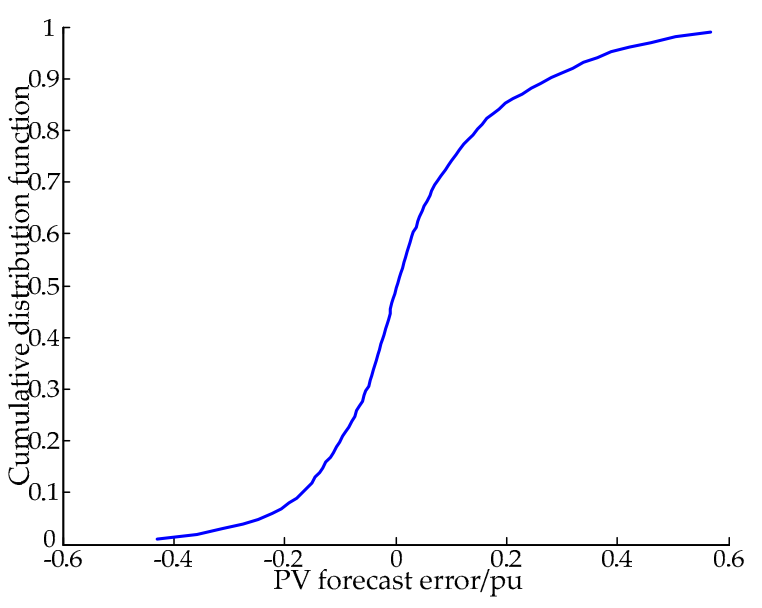

(b)

Figure 3. The forecast error cumulative distribution function curves of WP (a) and PV (b).

\section{Uncertain Scenario Set Description}

The combination of the WP output scenarios and PV output scenarios increase the number of formed scene sets and increase the difficulty of calculation. Therefore, this paper used the Latin hypercube sampling method to generate a large number of initial scenarios of the WP output and initial scenarios of PV output, and then used the simultaneous backward reduction method to reduce the scenarios.

\subsection{Scene Generation Based on Latin Hypercube Sampling}

There are two commonly used methods for sampling: (1) Monte Carlo sampling and (2) Latin hypercube sampling. Under the same sampling scale, random variable joint covering space of the Latin hypercube sampling method was larger than that of the Monte Carlo sampling method [38]. The Latin hypercube sampling method is essentially hierarchical. As shown in Figure 4, the core idea of sampling is to divide the cumulative curve into equal intervals on the cumulative probability scale $[0,1]$. Then, in order to ensure the sampling point covers the random distribution area of all input random variables, it is suggested to take samples randomly from each interval of the input distribution and force the sampling to represent the value of each interval.

The steps are as follows [39]:

Step 1: Let $x_{1}, x_{2}, \ldots, x_{T}$ be $T$ independent random variables, whose cumulative probability distribution function is:

$$
\Phi_{t}=F_{h}\left(x_{t}\right), \Phi_{t} \in[0,1], t=1,2, \ldots, T
$$

Step 2: Suppose $M$ is the sampling size and the vertical axis of the cumulative probability distribution function curve $\Phi_{t}=F_{h}\left(x_{t}\right)$ is divided into $M$ equal intervals, non-overlapping, and with a width of $\frac{1}{M}$, whose size is $\left[\frac{n-1}{M}, \frac{n}{M}\right], n=1,2, \ldots, M$. 
Step 3: The authors select the midpoint of each interval as the sampling value of $\Phi_{t}$ and calculate the sampling value of $x_{t}$ by taking the inverse function of the cumulative distribution function $\Phi_{t}=F_{h}\left(x_{t}\right)$, i.e., the $m$-th sampling value of $x_{t}$.

$$
x_{t m}=F_{h}^{-1}\left(\frac{m-0.5}{M}\right), t=1,2, \ldots, T
$$

All sampling values $x_{t m}$ form a $T \times M$ initial sampling matrix $X$.

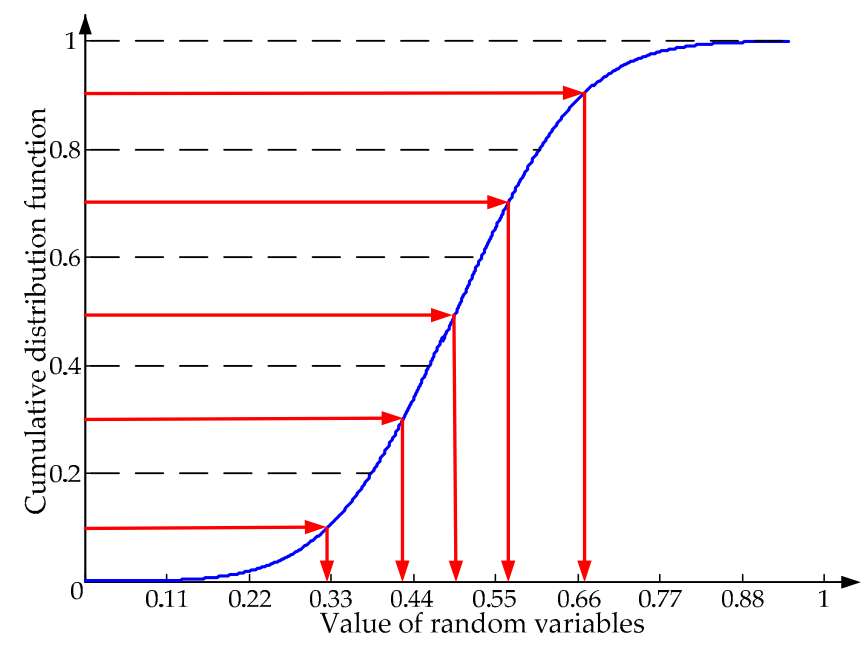

Figure 4. The structure of Latin hypercube sampling.

\subsection{Scenario Reduction Based on Simultaneous Backward Reduction Method}

A large number of time series scenarios with the same probability were obtained by sampling methods, which described the uncertainty of the WP output and PV output more accurately. However, the combination of the WP and PV output scenarios made the number of scenes increase sharply, which created low calculation efficiency. Therefore, it was possible to use the simultaneous backward reduction method to reduce the WP and PV scenarios. Lastly, we obtained the probability of each scenario. The steps are as follows [40]:

Step 1: The authors first get the large-scale scenarios $X=\left\{X_{1}, X_{2}, \ldots, X_{M}\right\}$ and set the number of scenarios to be deleted as $K$.

Step 2: In this step, the authors calculate the Kantorovich distance for each pair of scenarios:

$$
K D\left(X_{i}, X_{j}\right)=\sqrt{\sum_{t=1}^{T}\left(x_{t, i}-x_{t, j}\right)^{2}}
$$

where $X_{i}$ is the $i$-th scenario, and $x_{t, i}$ is the $t$-th element of scenario $i$.

Step 3: For any scenario, $X_{i}$, the authors compared the distance of the matching scene pair and then found scenarios closest to scenario, $X_{i}$. These scenarios are deleted according to the principle of scene reduction. Finally, the authors accumulate the probability of deleted scenes to the closest scene.

Step 4: Repeat step 3 until the number of deleted scenes are reached K. Finally, the authors obtain the reduced WP output scenarios, PV output scenarios, and the corresponding scenario probability.

\section{Reserve Capacity Quantitative Model Based on the Reliability Index}

Based on the scenarios established above, the system reliability was expressed by the expected energy not supplied (EENS) and the expected WP and PV curtailed (EWPPC). Based on reliability indexes and considering the uncertain factors of power system, the quantitative relationship between the reserve demand and reliability indexes was deduced. 


\subsection{The Expected Energy Not Supplied}

Operation reserve refers to the rapid active power response capacity reserved to meet the reliable and continuous power supply for the load. It can cope with the load and the renewable energy output fluctuation, generator outage fault, and so on [15]. If the prediction error of the renewable energy output in the system is too large or the generator is faulty, it leads to a power shortage in the system. At the same time, if the up-regulated reserve cannot meet the power shortage, then the loss of load occurs.

If the reserve capacity provided by the system at time $t$ under scenario $k$ is less than the power shortage, then the required shear load is:

$$
E E N S^{t}=\sum_{k=1}^{N_{k}} \beta_{k} \cdot \max \left\{P_{l, t}^{p r e}+\xi_{l, t}^{k}-P_{w, t}^{p r e}-\xi_{w, t}^{k}-P_{p v, t}^{p r e}-\xi_{p v, t}^{k}-\sum_{i} P_{t h, i, t}^{k}-\sum_{j} P_{g a, j, t}^{k}-P_{p s, o u t, t}^{k}+P_{p s, i n, t}^{k}-R_{u p, t}^{k}, 0\right\}
$$

where $R_{u p, t}^{k}$ is provided by the thermal power units, gas power units, and pumped storage unit in the normal operation.

$$
\begin{gathered}
R_{u p, t}^{k}=\sum_{i} R_{t h, i, t}^{+, k}+\sum_{j} R_{g a, j, t}^{+, k}+R_{p s, t}^{+, k} \\
\left\{\begin{array}{l}
R_{t h, i, t}^{+, k}=\min \left\{r_{t h, i}^{u p} \Delta t, P_{t h, i}^{\max }-P_{t h, i, t}^{k}\right\} \\
R_{g a, j, t, t}^{+, k}=\min \left\{r_{g a, j}^{u p} \Delta t, P_{g a, j}^{\max }-P_{g a, j, t}^{k}\right\} \\
R_{p s, t}^{+, k}=\min \left\{P_{p s, o u t}^{\max }\left(W_{p s, t}^{k}-W_{p s}^{\min }\right) / \Delta t\right\}
\end{array}\right.
\end{gathered}
$$

Assuming that $E_{0}^{t}$ is the minimum load shedding capacity at time $t$, according to the reliability requirements, then:

$$
\text { EENS }^{t} \leq E_{0}^{t}
$$

Equation (16) is the relationship between up-regulated reserve and reliability index of the system at time $t$.

$$
E_{0}^{t} \geq \sum_{k=1}^{N_{k}} \beta_{k}\left(P_{l, t}^{p r e}+\xi_{l, t}^{k}-P_{w, t}^{p r e}-\xi_{w, t}^{k}-P_{p v, t}^{p r e}-\xi_{p v, t}^{k}-\sum_{i} P_{t h, i, t}^{k}-\sum_{j} P_{g a, j, t}^{k}-P_{p s, o u t, t}^{k}+P_{p s, i n, t}^{k}-R_{u p, t}^{k}\right)
$$

where the minimum $R_{u p, t}^{k}$ is the minimum up-regulated reserve required by the system at time $t$ under scenario $k$ :

$$
R_{u p, d e m a n d}^{t}=\sum_{k=1}^{N_{k}} \beta_{k}\left(P_{l, t}^{p r e}+\xi_{l, t}^{k}-P_{w, t}^{p r e}-\xi_{w, t}^{k}-P_{p v, t}^{p r e}-\xi_{p v, t}^{k}-\sum_{i} P_{t h, i, t}^{k}-\sum_{j} P_{g a, j, t}^{k}-P_{p s, o u t, t}^{k}+P_{p s, i n, t}^{k}\right)-E_{0}^{t}
$$

\subsection{Expected Wind Power and PV Curtailed}

After the large-scale renewable energy is connected, the system peak shaving problem is prominent. Especially for systems with cogeneration units, the peak shaving depth of the system is limited due to the operation mode in winter, which intensifies wind and PV curtailment [41]. Therefore, the reasonable arrangement of the system's operation reserve is beneficial to reduce wind and solar curtailment.

According to the above scene set, the expected WP and PV curtailment at time $t$ under scenario $k$ is:

$$
\operatorname{EWPPC}^{t}=\sum_{k=1}^{N_{k}} \beta_{k} \cdot \max \left\{P_{w, t}^{p r e}+\xi_{w, t}^{k}+P_{p v, t}^{p r e}+\xi_{p v, t}^{k}+\sum_{i} P_{t h, i, t}^{k}+\sum_{j} P_{g a, j, t}^{k}+P_{p s, o u t, t}^{k}-P_{p s, i n, t}^{k}-P_{l, t}^{p r e}-\xi_{l, t}^{k}-R_{d n, t^{\prime}}^{k} 0\right\}
$$

where $R_{d n, t}^{k}$ is provided by the thermal power units, gas power units, and pumped storage unit in normal operation. 


$$
\begin{gathered}
R_{d n, t}^{k}=\sum_{i} R_{t h, i, t}^{-, k}+\sum_{j} R_{g a, j, t}^{-, k}+R_{p s, t}^{-, k} \\
\left\{\begin{array}{l}
R_{t h, i, t}^{-, k}=\min \left\{r_{t h, i}^{d n} \Delta t, P_{t h, i, t}^{k}-P_{t h, i}^{\min }\right\} \\
R_{g a, j, t}^{-, k}=\min \left\{r_{g a, j}^{d n} \Delta t, P_{g a, j, t}^{k}-P_{g a, j}^{\min }\right\} \\
R_{p s, t}^{-, k,}=\min \left\{P_{p s, i n}^{\max }\left(W_{p s}^{\max }-W_{p s, t}^{k}\right) / \Delta t\right\}
\end{array}\right.
\end{gathered}
$$

Assuming that $C_{0}^{t}$ is the minimum wind and PV curtailment at time $t$, according to the reliability requirements, then we can find that:

$$
E W P P C^{t} \leq C_{0}^{t}
$$

Equation (22) is the relationship between the down-regulated reserve and reliability index of the system at time $t$.

$$
C_{0}^{t} \geq \sum_{k=1}^{N_{k}} \beta_{k}\left(P_{w, t}^{p r e}+\xi_{w, t}^{k}+P_{p v, t}^{p r e}+\xi_{p v, t}^{k}+\sum_{i} P_{t h, i, t}^{k}+\sum_{j} P_{g a, j, t}^{k}+P_{p s, o u t, t}^{k}-P_{p s, i n, t}^{k}-P_{l, t}^{p r e}-\xi_{l, t}^{k}-R_{d n, t}^{k}\right)
$$

where the minimum $R_{d n, t}^{k}$ is the minimum down-regulated reserve required by the system at time $t$, we can find that:

$$
R_{d n, \text { demand }}^{t}=\sum_{k=1}^{N_{k}} \beta_{k}\left(P_{w, t}^{p r e}+\xi_{w, t}^{k}+P_{p v, t}^{p r e}+\xi_{p v, t}^{k}+\sum_{i} P_{t h, i, t}^{k}+\sum_{j} P_{g a, j, t}^{k}+P_{p s, o u t, t}^{k}-P_{p s, i n, t}^{k}-P_{l, t}^{p r e}-\xi_{l, t}^{k}\right)-C_{0}^{t}
$$

\section{The Coordination and Optimization Model of Power Generation and Reserve}

In this paper, the system reserve capacity demand was divided into up-regulated reserve and down-regulated reserve, which were used to deal with load shortage and renewable energy output climbing events, respectively. Considering the coordination between reserve dispatching and generation dispatching, the system reserve plan can be determined while units were committed and the output plan was formulated. Therefore, the model obtained the system units generation plan, reserve plan, and minimum reserve demand of the system at each moment, simultaneously. Based on the scenario set, the following coordinated optimization model of power generation and reserve was established, which considered the reliability and economic efficiency of the system.

\subsection{Objective Function}

In order to realize the maximum absorption of the renewable energy and economic efficiency of the system's operation, the objective function of the model comprehensively considered the minimum amount of WP and PV power curtailment, as well as the lowest total operation cost of thermal power units, gas power units and PSPS.

$$
\min f=\sum_{k=1}^{N_{k}} \beta_{k} \sum_{t}\left(C_{t h, t}^{k}+C_{g a, t}^{k}+C_{p s, t}^{k}+\lambda_{w} P_{w, t}^{c u t, k}+\lambda_{p v} P_{p v, t}^{c u t, k}+\lambda_{l} P_{l, t}^{c u t, k}\right)
$$

The specific calculation formula of operating cost of various units and equipment is shown in Equation (25).

$$
\left\{\begin{array}{l}
C_{t h, t}^{k}=\sum_{i}\left[a_{t h, i}\left(P_{t h, i, t}^{k}\right)^{2}+b_{t h, i} P_{t h, i, t}^{k}+c_{t h, i}\right] \\
C_{g a, t}^{k}=\sum_{j}\left[a_{g a, j}\left(P_{g a}^{k}{ }_{g a, t, t}\right)^{2}+b_{g a, j} P_{g a, j, t}^{k}+c_{g a, j}\right] \\
C_{p s, t}^{k}=w_{o u t} P_{p s, o u t, t}^{k} U_{o u t, t}+w_{i n} P_{p s, i n, t}^{k} U_{i n, t}
\end{array}\right.
$$




\subsection{Constraints}

\subsubsection{Operation Constraints of Thermal Power Units}

The upper and lower limits of output constraints and the climb rate constraints of thermal power units are mainly considered in the model. The specific constraints are as follows:

$$
\begin{gathered}
P_{t h, i}^{\min } \leq P_{t h, i, t}^{k} \leq P_{t h, i}^{\max } \\
-r_{t h, i}^{d n} \cdot \Delta t \leq P_{t h, i, t+1}^{k}-P_{t h, i, t}^{k} \leq r_{t h, i}^{u p} \cdot \Delta t
\end{gathered}
$$

Large thermal power units are the main generators of the power system. It takes 1-2 days for the units from the cold reserve state of the boiler to the grid connection, which may take longer or longer due to the impact of scheduling instructions [42]. Therefore, the model in this paper did not consider unit commitment. Once the thermal power units are determined to operate, the intra-day change did not occur.

\subsubsection{Operation Constraints of Gas Power Units}

1. Unit start and stop time constraint

$$
\left\{\begin{array}{l}
\sum_{\substack{s=t \\
t+T_{g a, j}^{o n}-1}}^{\substack{o f \\
t+T_{g a f}^{o f a}-1}} U_{g a, j, s} \geq T_{g a, j}^{o n} \cdot\left(U_{g a, j, t}-U_{g a, j, t-1}\right) \\
\sum_{s=t}\left(1-U_{g a, j, s}\right) \geq T_{g a, j}^{o f f} \cdot\left(U_{g a, j, t-1}-U_{g a, j, t}\right)
\end{array}\right.
$$

2. Other constraints

The constraints of gas power unit also includes the upper and lower limits of output constraints and the climb rate constraints, which are similar to the constraints of thermal power unit, so it will not be repeated here.

\subsubsection{Constraints of Pumped Storage Power Station}

1. Reservoir capacity balance constraints

$$
W_{p s, t}^{k}=W_{p s, t-1}^{k}+\mu_{p s} P_{p s, i n, t}^{k} U_{i n, t} \Delta t-P_{p s, o u t, t}^{k} U_{o u t, t} \Delta t
$$

2. Reservoir capacity constraints

$$
W_{p s}^{\max } \leq W_{p s, t}^{k} \leq W_{p s}^{\min }
$$

3. State constraints of generation/pumping

In this paper, a virtual generator and motor are used to represent the two working states of the power generation and pumping, and they can only be in one working mode at the same time.

$$
U_{i n, t}+U_{o u t, t} \leq 1
$$

4. Power constraints of generation/pumping

The power generation of PSPS can change continuously, but the pumping power is usually a constant value.

$$
\left\{\begin{array}{l}
P_{p s, \text { in }, t}^{k}=P_{p s, \text { in }}^{\max } \\
0 \leq P_{p s, \text { out }, t}^{k} \leq P_{p s, o u t}
\end{array}\right.
$$




\subsubsection{System Constraints}

1. Electric load balance constraints

$$
\sum_{i} P_{t h, i, t}^{k}+\sum_{j} P_{g a, j, t}^{k}+\left(P_{w, t}^{p r e}-P_{w, t}^{c u t, k}\right)+\left(P_{p v, t}^{p r e}-P_{p v, t}^{c u t, k}\right)+P_{p s, o u t, t}^{k}=\left(P_{l, t}^{p r e}-P_{l, t}^{c u t, k}\right)+P_{p s, i n, t}^{k}
$$

2. Reliability constraints

$$
\left\{\begin{array}{l}
\sum_{i} R_{t h, i, t}^{+, k}+\sum_{j} R_{g a, j, t}^{+, k}+R_{p s, t}^{+, k} \geq R_{u p, d e m a n d}^{t} \\
\sum_{i} R_{t h, i, t}^{-, k}+\sum_{j} R_{g a, j, t}^{-, k}+R_{p s, t}^{-, k} \geq R_{d n, \text { demand }}^{t}
\end{array}\right.
$$

3. Network security constraints

$$
P_{d, \text { min }} \leq P_{d, t}^{k} \leq P_{d, \text { max }}
$$

\subsection{Calculating Procedures}

In this paper, we established a coordinated dispatching model of the WP-PV-pumped storage system with WP, PV power, thermal power units, and gas power units. The ultra-short term prediction error probability density distributions of the WP output and PV output were analyzed by the nonparametric kernel density estimation method and the uncertainties were described by a scenario set. Considering the operation constraints of various power sources and the minimum amount of WP and PV power curtailment, as well as the lowest total operation cost, the coordinated dispatching model of power generation and reserve was established. The unit operating cost was transformed into a linear function by piecewise linearization and the reliability constraint was transformed into the inequality constraint by derivation. Therefore, the whole problem was transformed into a mixed integer linear programming problem, which was solved by using MATLAB 2016a programming and the Yalmip toolbox to call the solver CPLEX12.8.

\section{Case Study}

\subsection{Parameters of the Calculation Example}

The examples in this paper included a 200 MW wind farm, a 40 MW PV power station, four thermal power units with a total installed capacity of $1290 \mathrm{MW}$, two gas power units with a total installed capacity of $120 \mathrm{MW}$, and a pumped storage unit with a maximum capacity of $150 \mathrm{MW} \cdot \mathrm{h}$, a maximum pumping power of $30 \mathrm{MW}$, and a maximum generation power of $30 \mathrm{MW}$. The specific parameters of the units are shown in Table A1.

Examples in this paper verified the practicability of the model from three working conditions. Due to the small installed capacity of PV power station, the impact caused by its uncertainty was far less than that caused by WP, so the impact of PV output uncertainty was not considered. The three working conditions were as follows: ordinary operating conditions, the working conditions with continuous large wind power output, and the working conditions with continuous a small wind power output. The day-ahead WP output forecast data under different working conditions is shown in Figure 5. The day-ahead load forecast data and the day-ahead PV output forecast data are shown in Figure 6. 


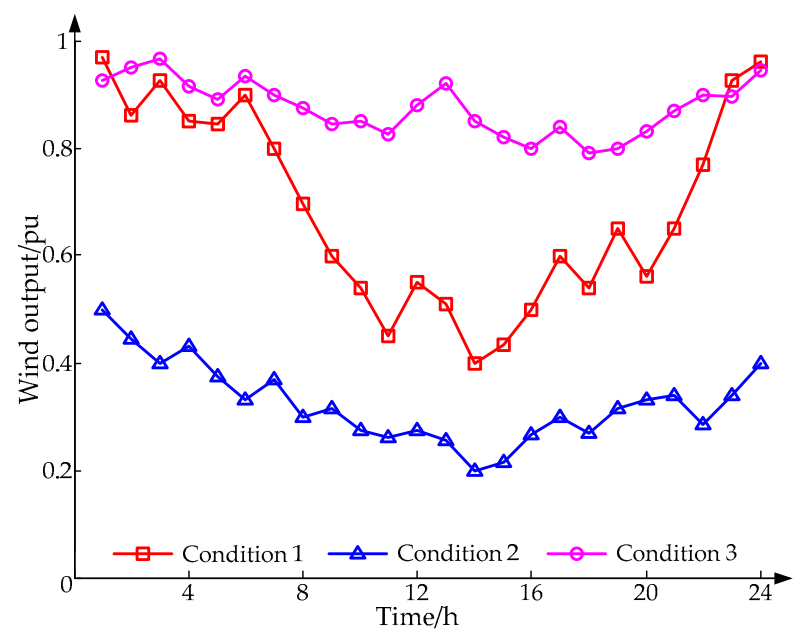

Figure 5. Day-ahead forecast of the WP output under different working conditions.

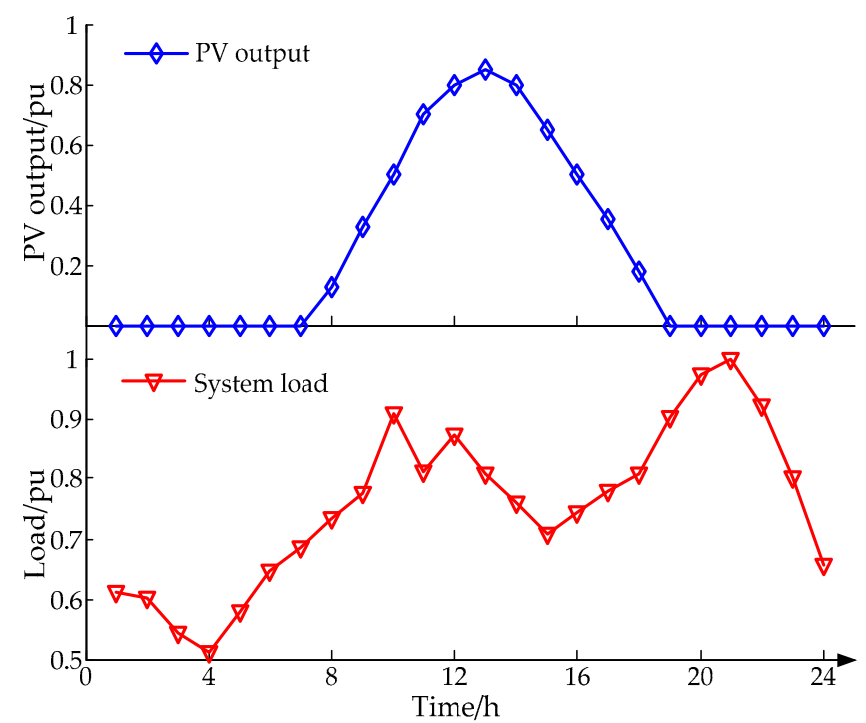

Figure 6. Day-ahead forecast of the PV output and load.

\subsection{Scenario Generation and Reduction}

The authors used a multi-scene model to simulate the uncertainty of the WP output and PV output. In this section, the WP output under ordinary operating conditions was used as an example. The LHS method was adopted to obtain 200 WP output scenes and PV output scenes, respectively. It can be seen from Figure 7 that the variation trend of the scene simulated by LHS method was roughly the same, except that the output in each period appeared with corresponding deviation within a certain confidence interval.

After simultaneous backward reduction, three WP output curves and three PV output curves were obtained, as shown in Figure 8. The scenario probability corresponded to the reduced scenarios, as shown in Table 1. 


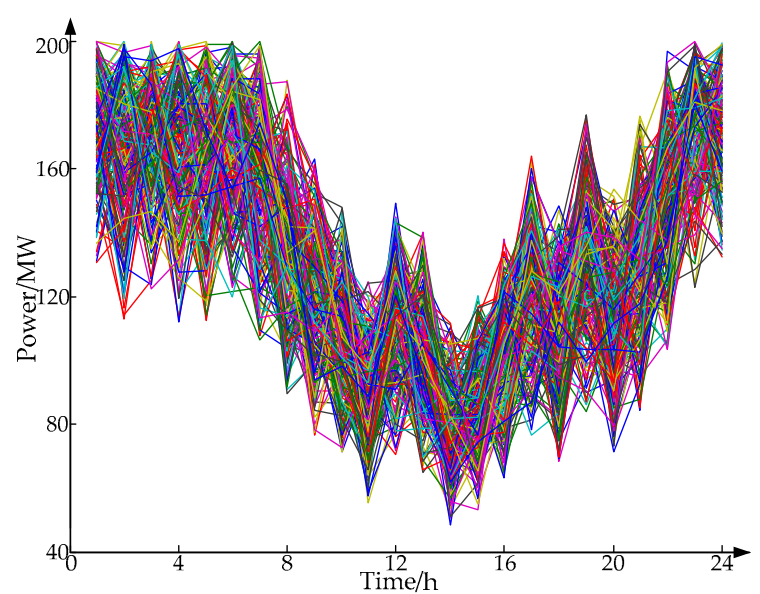

(a)

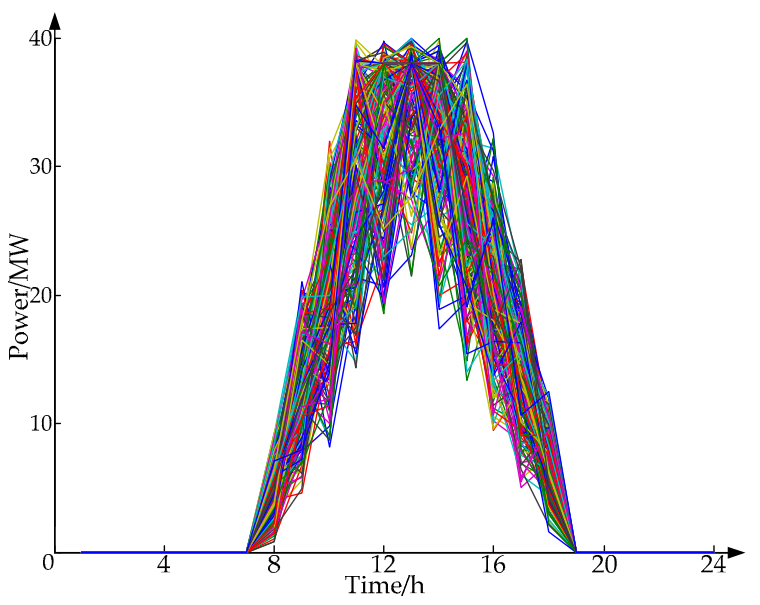

(b)

Figure 7. The WP scenarios (a) and the PV scenarios (b) based on LHS method.

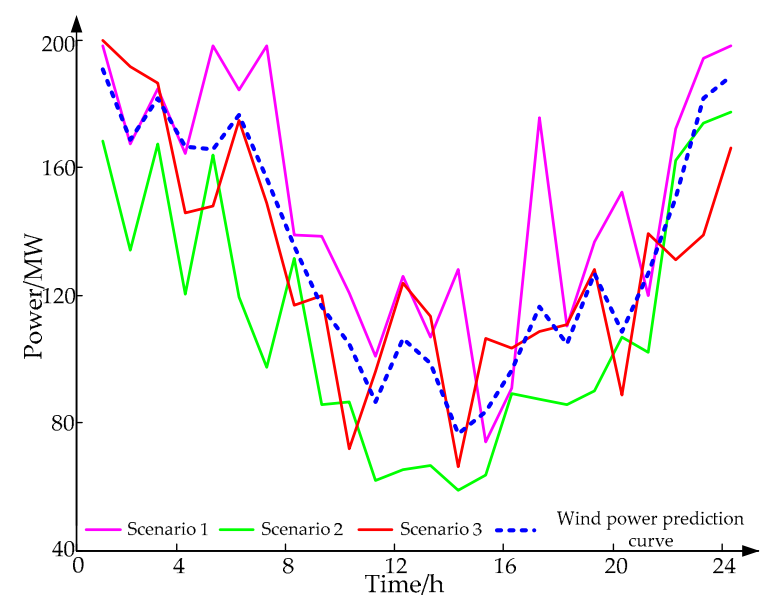

(a)

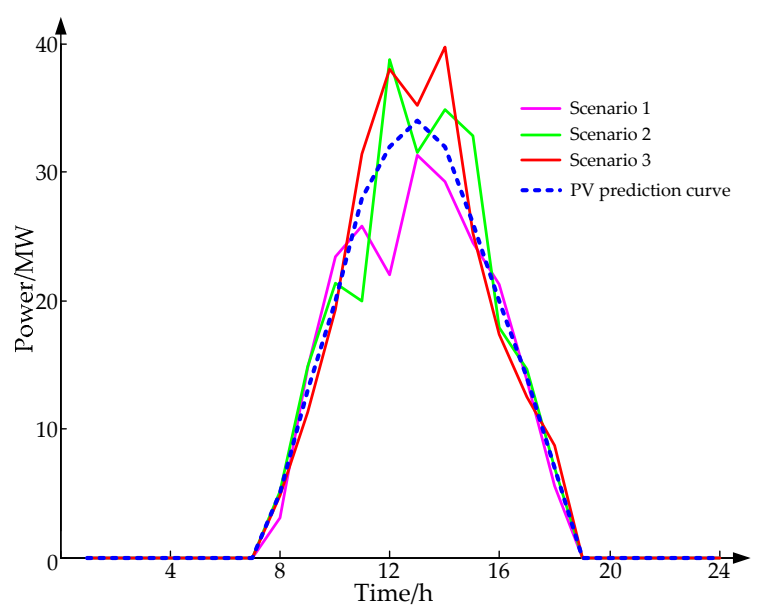

(b)

Figure 8. Reduced WP output scenarios (a) and PV output scenarios (b).

Table 1. The probability of the WP scenarios and PV scenarios reduced.

\begin{tabular}{ccc}
\hline & WP Reduction Scenario & PV Reduction Scenario \\
\hline Scenario 1 & 0.616 & 0.342 \\
Scenario 2 & 0.176 & 0.340 \\
Scenario 3 & 0.208 & 0.318 \\
\hline
\end{tabular}

Similarly, the WP output scenarios and its corresponding scenario probability can be obtained under the other working conditions.

\subsection{The Dispatching Test Results under Different Working Conditions}

In this section, the authors analyzed the output status of each power source, the working status of PSPS, and the reserve condition from the perspective of three working conditions. In order to verify the validity of the model in this paper, two different alternative decision making schemes were selected for comparative analysis under the same calculation example and parameters. Scheme 1 was the operation reserve capacity scheme proposed in this paper. Scheme 2 was a deterministic reserve capacity scheme, whose operating reserve is shown in the following formula.

$$
R_{\text {demand }}^{+,-}=P_{l, t}^{p r e} \times 10 \%+P_{w, t}^{p r e} \times 15 \%+P_{p v, t}^{p r e} \times 15 \%
$$




\subsubsection{Ordinary Operating Conditions}

The output of each power source under ordinary operating conditions is shown in Figure 9. Under ordinary operating conditions, the WP had a strong anti-peak-regulating property, so its output was large at night and low in the morning. However, the night load level was low, which seriously compresses the generating space of thermal power units, so the output of thermal power units showed a downward trend. At this time, the down-regulated reserve provided by the thermal power unit was lower. If the down-regulated reserve was not supplemented, there was wind curtailment. The pumped storage unit provided a major down-regulated reserve capacity through pumping operations, converting wind curtailment electricity into potential energy and storing it. During 9:00-12:00, the first load peak occurred and a large number of up-regulated reserves were consumed. Thermal power units all operated at a high output level and, at this time, up-regulated reserve units were mainly provided by gas power units and pumped storage units. When the gas power units ran at a lower output level, they provided a large number of up-regulated reserves to cope with load surge events. Similarly, during 19:00-22:00, the second load peak occurred, and thermal power units operated at the maximum output level. At this time, gas power units participated in dispatching to provide up-regulated reserve, while pumped storage unit participates in the dispatching to reduce the load level.

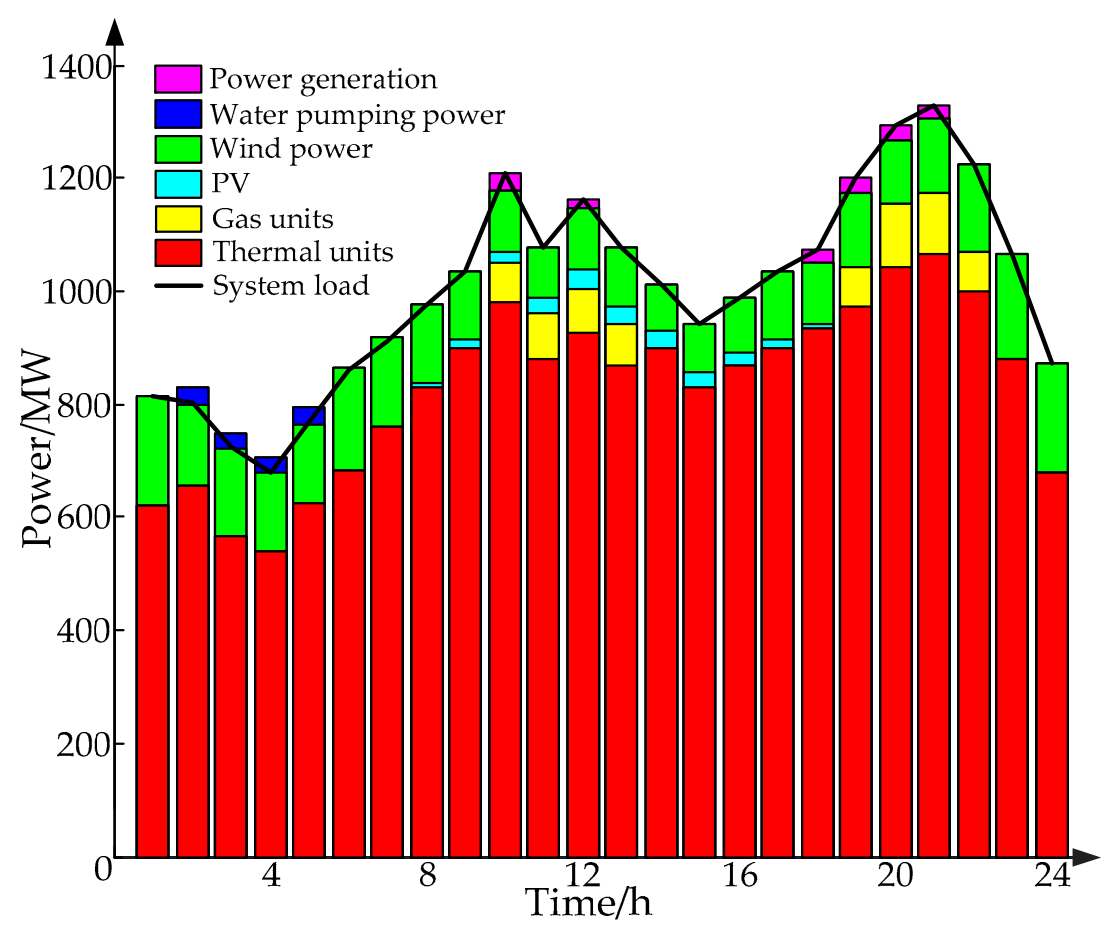

Figure 9. Output of each power source under ordinary operating condition.

It can be seen from Figure 10 that the PSPS increased the load level by pumping water during the period of abundant WP at night, while in peak load periods, such as the period of 9:00-12:00 and 19:00-22:00, the PSPS reduced the load level through generation. Therefore, the PSPS had a significant effect of peak load cutting, which provided great flexibility for the operation and scheduling of power system.

The comparison between the up-regulated reserve supply and demand curves and the down-regulated reserve supply and demand curves at each moment is shown in Figure 11. By comparing the results of the two kinds of reserve capacity decision-making schemes, it can be seen that the reserve capacity demand obtained by the traditional deterministic scheme was lower than that obtained by the optimized scheme in this paper. The reserve capacity supply obtained by the traditional scheme was also smaller than the result of the scheme in this paper. Because the 
scheme proposed in this paper met the system power balance and reserve capacity constraints under all scenarios, there were many units involved in the dispatching, which led to the opening of some small capacity units with high operating costs. Therefore, compared with the traditional scheme, the optimized scheme proposed in this paper increased the total operating cost.

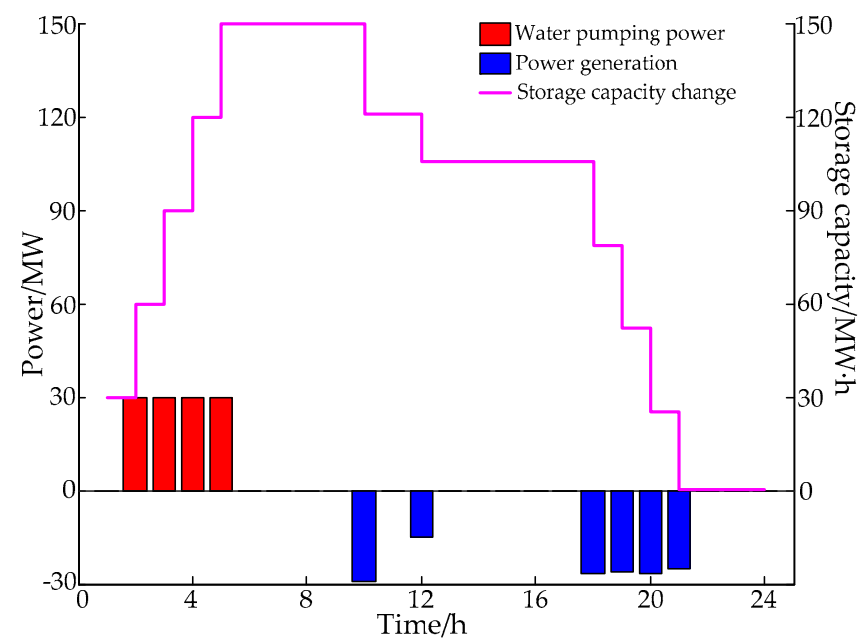

Figure 10. Changes of pumping and generating power and storage capacity of the PSPS.

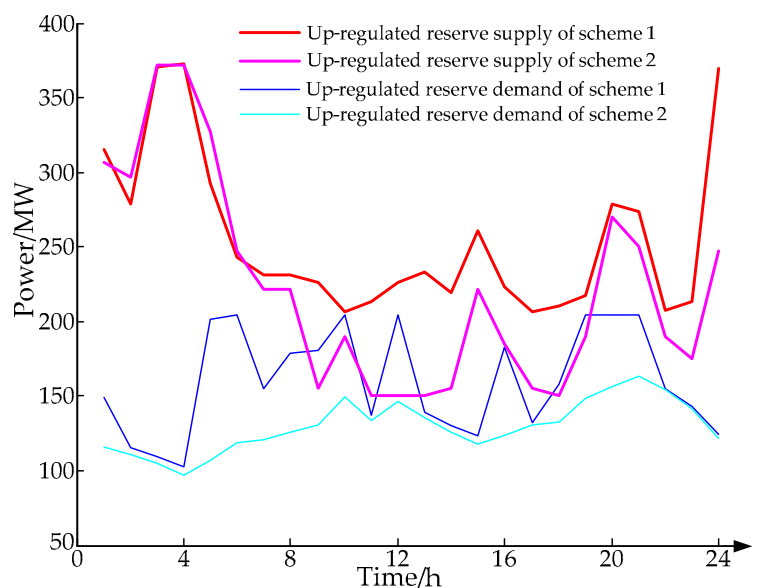

(a)

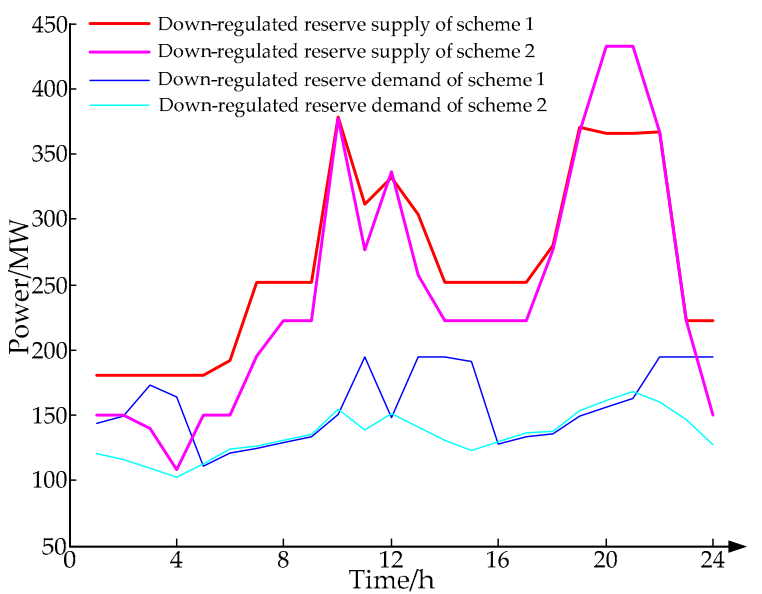

(b)

Figure 11. Comparison of reserve demand and supply under different scheme: (a) Up-regulated reserve comparison; (b) Down-regulated reserve comparison.

\subsubsection{The Working Conditions with Continuous Large Wind Power Output}

The output of each power source under the second working condition is shown in Figure 12. It can be seen from Figure 12 that the WP output was large throughout the day. Therefore, in order to absorb more WP, the generation space of thermal power units had to be compressed. However, the load at night was low and thermal power units were at the minimum output level. In order to maintain the operation of thermal power units and meet the reserve capacity demand, WP was reduced. PSPS stored energy by pumping water during 1:00-4:00, which absorbed excess WP to a certain extent. However, due to capacity and pumping power rate restrictions, it was difficult to fully absorb WP. Due to the high WP output, thermal power units were enough to bear the change of load, so there was no gas power unit scheduling throughout the day. In the second peak load, the pumped storage unit generated electricity instead of the gas power unit, which not only ensured the reliability of the power system but also reduced the generation cost of the gas power unit and ensured the economic efficiency of the system. 


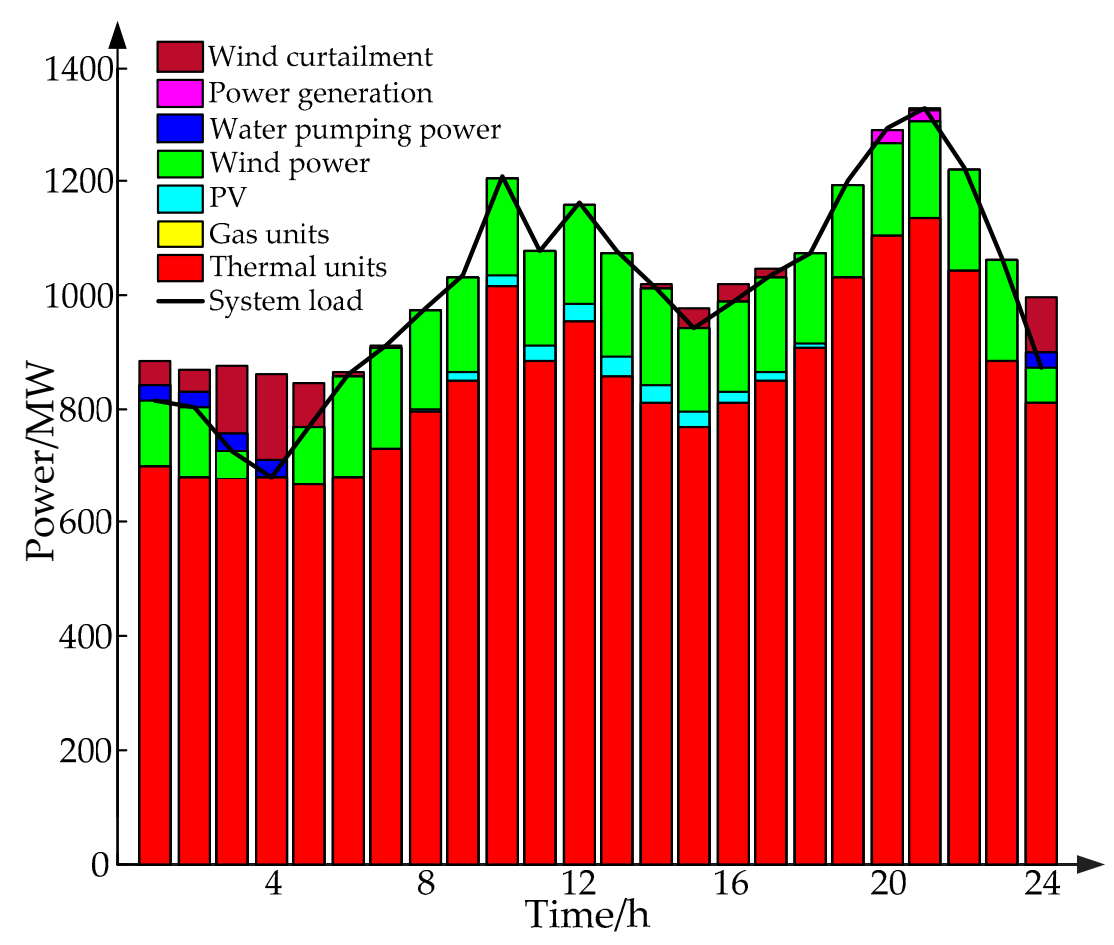

Figure 12. Output of each power source under WP continuous high output condition.

The changes of pumping, power generation, and storage capacity of the PSPS under this working condition are shown in Figure 13. It can be seen that the PSPS absorbs part of the WP through pumping operation during the night wind curtailment period. However, the WP output throughout the day is relatively high, so during 14:00-17:00, the PSPS reached the maximum storage capacity, and there is no space to store excess WP, thus causing certain wind curtailment. At 24:00, the storage capacity of the pumping and storage plant reached its maximum, which may have had a negative impact on WP consumption the next day. If the WP output was still at a high level, it caused more wind curtailment.

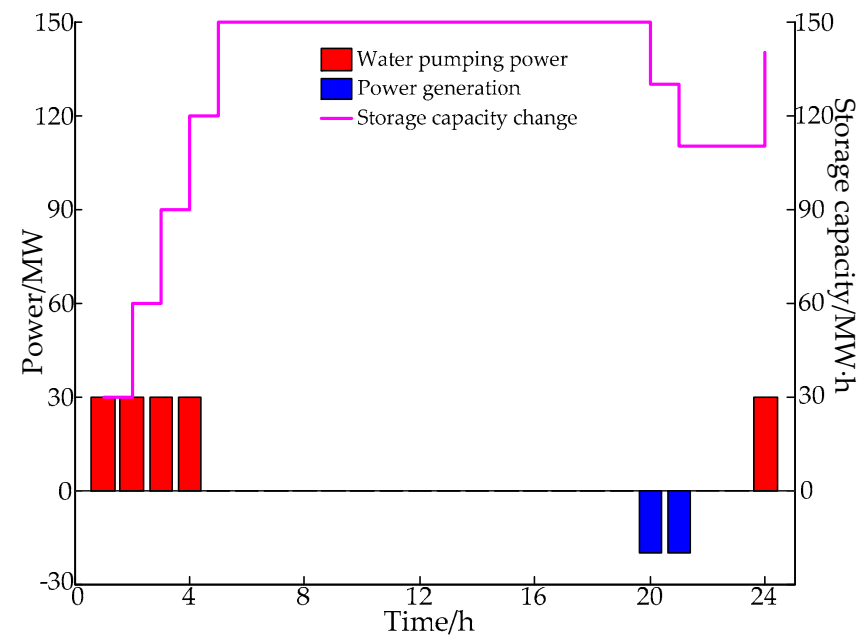

Figure 13. Changes of pumping and generating power and storage capacity of the PSPS.

The comparison between the up-regulated reserve supply and demand curves and the down-regulated reserve supply and demand curves at each moment is shown in Figure 14. Due to the large WP output, the net load was lower, and the thermal power unit output was at a low level, so the up-regulated reserve was higher, and the down-regulated reserve supply capacity was lower. High WP output increased the uncertainty of the system and the reserve demand. However, the reserve results 
obtained by the traditional deterministic scheme were too conservative, which may have led to the shortage of reserve in the actual operation.

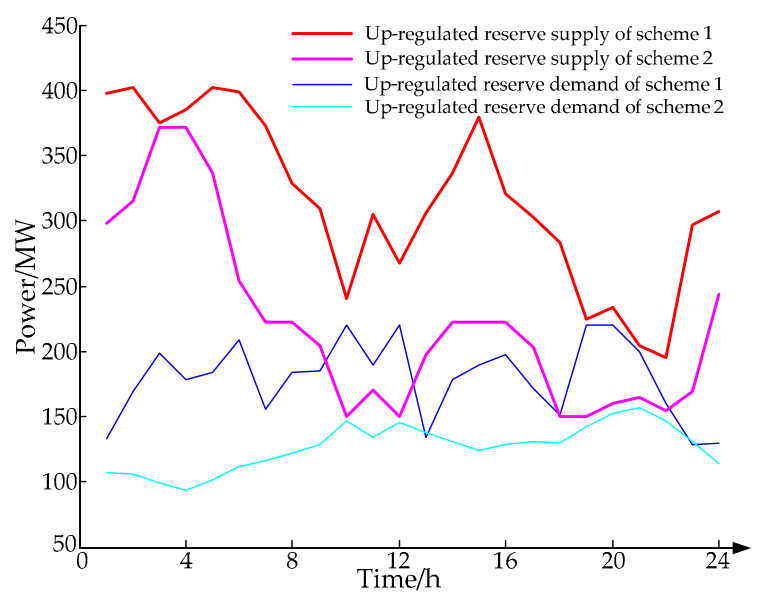

(a)

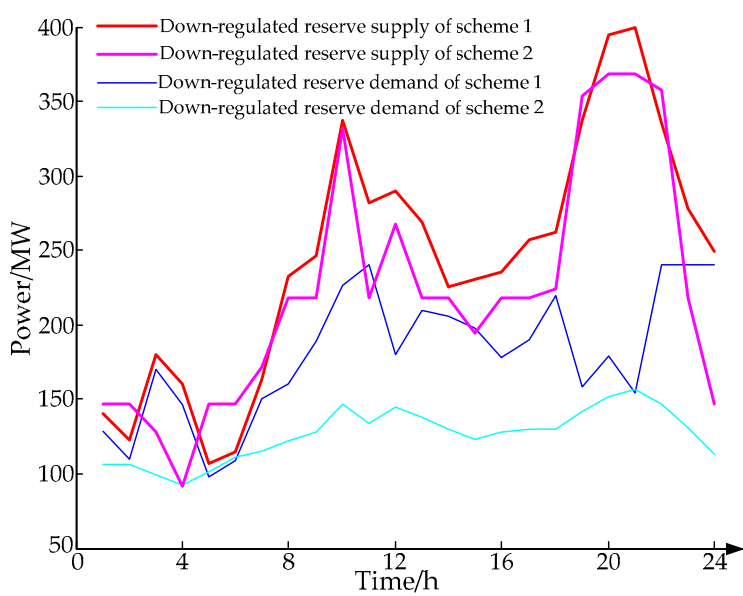

(b)

Figure 14. Comparison of reserve demand and supply under different schemes: (a) Up-regulated reserve comparison; (b) Down-regulated reserve comparison.

\subsubsection{The Working Conditions with Continuous Small Wind Power Output}

The output of each power source under the third working condition is shown in Figure 15. In this working condition, the all-day output of WP was at a low level, which brought great pressure to the generation scheduling of thermal power units. At night, WP output was low and the thermal power units increased output to balance the load demand. During the daytime, during the two peak load periods and thermal power units were at a high output level. In order to ensure the reserve capacity, the pumped storage unit and gas power units participated in the dispatching. The pumped storage unit reduced the load level and the gas power units provided reserve capacity for the power system and increased the flexibility of the power system. WP was fully consumed by the coordinated dispatching of power generation and reserve capacity without affecting the reliability of the power system.

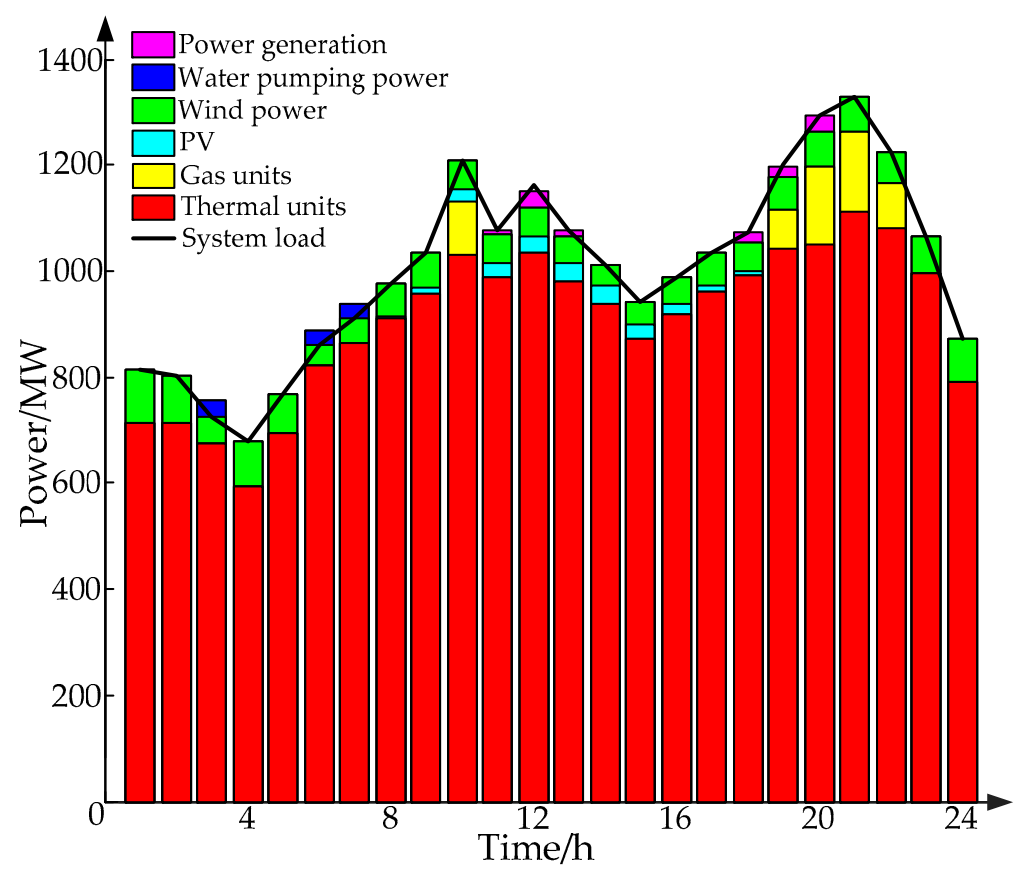

Figure 15. Output of each power source under wind power continuous low output condition. 
As shown in Figure 16, due to the small WP output level, although the PSPS carried out energy storage, the storage capacity did not reach the maximum value, and the PSPS was underutilized, which reduced the generation capacity available at the peak load in the daytime.

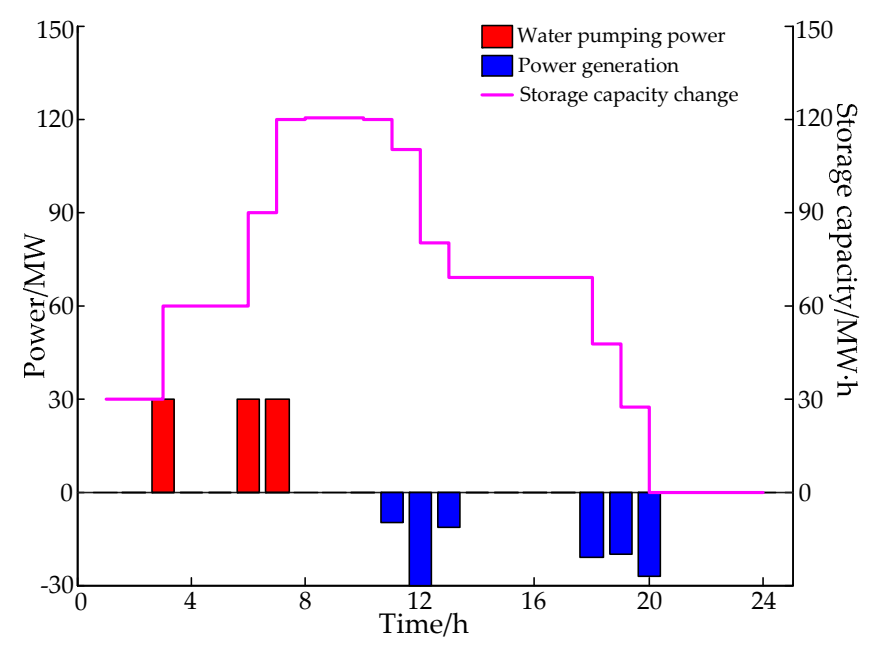

Figure 16. Changes of pumping and generating power and storage capacity of the PSPS.

The comparison between the up-regulated reserve supply and demand curves, and the down-regulated reserve supply and demand curves at each moment is shown in Figure 17. Due to the low WP output, the net load was relatively high and the thermal power unit was output at a higher level. Therefore, the down-regulated reserve supply capacity was larger, while the up-regulated reserve supply capacity was lower. The scheme in this paper met the reserve capacity constraints in all scenarios. Although the traditional deterministic scheme added additional reserve requirements, it provided less reserve capacity, which means there may have been an insufficient reserve in the actual operation.

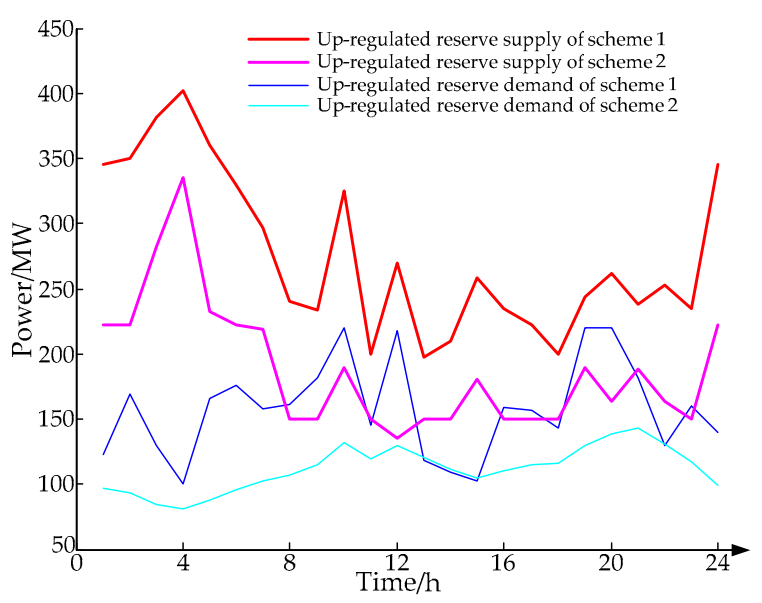

(a)

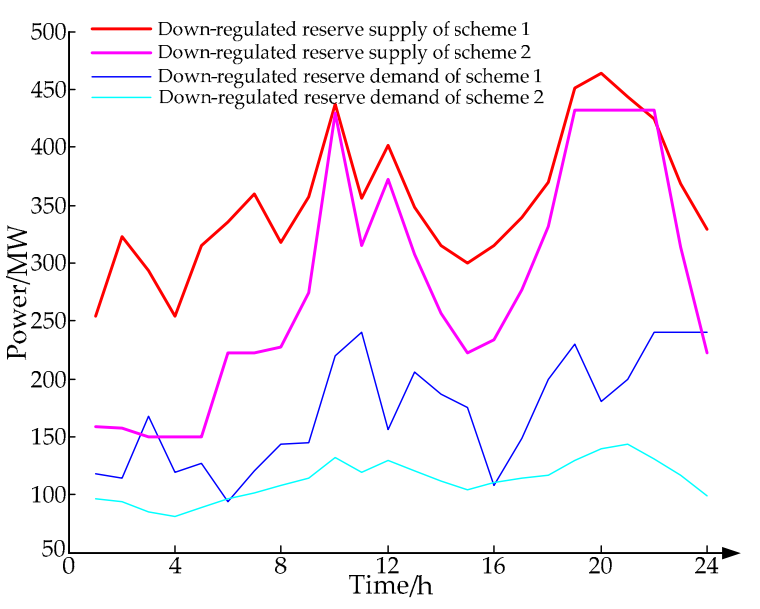

(b)

Figure 17. Comparison of reserve demand and supply under different schemes: (a) Up-regulated reserve comparison; (b) Down-regulated reserve comparison.

\section{Conclusions}

In order to solve the dispatching problem of unit outputs and reserve capacity decisions caused by large-scale WP and PV power in the power system, this paper innovatively combined the non-parametric kernel density estimation method and scenario method to describe the uncertainty of renewable energy output, based on the multi-scenario analysis method. In addition, a new method to determine the 
reserve capacity demand was proposed to derive the quantitative relationship between the reserve demand and the reliability index of power system. Through example analysis, we can draw the following conclusions:

- The non-parametric kernel density estimation method did not need to assume the distribution model of variables and had little limitation on the model. According to Figure 2, the modeling process of the non-parametric method was simple and was subject to little interference from external factors. Compared with the parametric method, the results obtained by the non-parametric method had a small error and was highly practical.

- According to Figures 9, 12 and 15, it can be seen that the PSPS achieved peak load cutting and valley load reduction, as well as reduced the peak-valley difference of load. The gas power unit had flexible adjustment ability and provided a large amount of reserve capacity. Therefore, globally, the number of gas power units and PSPSs were appropriately increased so that they can participate in power grid dispatching, which effectively relieved peak pressure of thermal power units and further reduced renewable energy waste and load cutting accidents.

- Compared with the traditional deterministic alternative decision method, the method proposed in this paper effectively solved its blindness. By comparing Figure 11, Figure 14, and Figure 17, we can clearly find that the method proposed in this paper met the system power balance constraint and reserve capacity constraint in all scenarios, and the results of the reserve demand and supply were higher than those of the traditional deterministic reserve decision method. Therefore, there was no shortage of reserve in the operation process. The method proposed in this paper is of great practical value for active power dispatching of power systems with large-scale renewable energy sources.

At present, the complementary power generation technology of new energy system and energy storage system is not fully mature. Moreover, due to the complexity of problems, the actual WP-PV-storage complementary power generation technology has other factors that need to be considered. The depth and breadth of the research are limited and further studies can be carried out in the follow-up work as follows:

- The correlation between WP output and PV output was not considered. WP output and PV output have certain complementarity, i.e., negative correlation. In the follow-up research, different Copula functions can be introduced to form the WP-PV joint probability distribution model according to the situation, which can better fit with the engineering practice.

- The actual power system parameters should be used for verification and more reference examples should be added, so that the analysis of the problem are more convincing and targeted.

- The coordinated scheduling problem proposed in this paper is an unusually complex mixed integer nonlinear programming problem. When the system size is large, it is very difficult to directly optimize and solve the problem. Therefore, it is urgent to seek an optimization algorithm to solve this problem.

Author Contributions: All of the authors have contributed to this research. Conceptualization, D.C. and F.X.; methodology, Y.Z. and W.G.; software, Y.Z. and P.H.; writing-original draft preparation, P.H.; writing-review and editing, Y.Z. and P.H.; supervision, F.X.; data curation, W.G.; funding acquisition, W.G. All authors have read and agreed to the published version of the manuscript.

Funding: This research was funded by the State Grid Liaoning Electric Power Co., Ltd. Technology Project (NO. SGTYHT/17-JS-199).

Acknowledgments: The authors give their thanks to Xiaorong Hao, Pinchao Zhao, Shengkai Guo and Panfeng Liao for giving valuable suggestions.

Conflicts of Interest: The authors declare no conflict of interest. 


\section{Nomenclature}

$a_{t h, i} / b_{t h, i} / c_{t h, i}$

$a_{g a, j} / b_{g a, j} / c_{g a, j}$

$C_{t h, t}^{k}$

$C_{g a, t}^{k}$

$C_{p s, t}^{k}$

$N_{k}$

$P_{l . t}^{p r e}$

$P_{w, t}^{p p r e}$

$P_{p v, t}^{\text {wre }}$

$p v, t$
$P_{\text {th }}^{k}, \mathrm{it}$

$P^{k}{ }^{k}, i, t$

$P_{p s, o u t, t}^{k}$

$P_{p s, i n, t}^{k}$

$P_{\text {th }, i}^{\min }$

th, $i$
max

th,i
pmin

$P_{g a, j}$

$P \max$

ga,j

Pmax

$P_{p s, i n}^{\max }$

Ps,in

$p s, i n$
$P^{c u t, k}$

$P^{\text {cut, } k}$

$P_{p v, t}$
$P^{c u t, k}$

$P_{l, t}^{c u t, k}$

$P_{d, t}^{k}$

$P_{d, \text { min }} / P_{d, \text { max }}$

$R_{u p, t}^{k}$

$R_{t h, i, t}^{+, k}$

$R_{g a, j, t}^{+, k}$

$R_{p s, t}^{+, k}$

$R_{d n, t}^{k}$

$R_{t h, i, t}^{-, k}$

$R_{g a, j, t}^{-, k}$

$R_{p s, t}^{-, k}$

$r_{t h, i}^{u p}$

$r_{t h, i}^{d n}$

$r_{g a, j}$

$r_{g a, j}^{d n}$

$T_{g a, j}^{o n} / T_{g a, j}^{o f f}$

$U_{g a, j, t}$

$U_{\text {out }, t} / U_{i n, t}$

$W_{p s, t}^{k}$

$p s, t$
$W_{p s}^{\text {min }}$ the second-order fitting coefficients of the operating cost of thermal power unit $i$

the second-order fitting coefficients of the operating cost of gas power unit $j$

operation cost of thermal power units at time $t$ under scenario $k$ (USD)

operation cost of gas power units at time $t$ under scenario $k$ (USD)

operation cost of PSPS at time $t$ under scenario $k$ (USD)

total number of scenarios

predicted value of load at time $t$ (MW)

predicted output of WP at time $t$ (MW)

predicted output of PV at time $t$ (MW)

output of thermal power unit $i$ at time $t$ under scenario $k$ (MW)

output of gas power unit $j$ at time $t$ under scenario $k(\mathrm{MW})$

generation power of the PSPS at time $t$ under scenario $k(\mathrm{MW})$

pumped storage power of the PSPS at time $t$ under scenario $k$ (MW)

minimum output operating limits of thermal power unit $i(\mathrm{MW})$

maximum output operating limits of thermal power unit $i(\mathrm{MW})$

minimum output operating limits of gas power unit $j(\mathrm{MW})$

maximum output operating limits of gas power unit $j(\mathrm{MW})$

maximum generation power of PSPS (MW)

maximum storage power of PSPS (MW)

curtailed WP at time $t$ under scenario $k$ (MW)

curtailed PV at time $t$ under scenario $k$ (MW)

load shedding power at time $t$ under scenario $k$ (MW)

power of line $d$ at time $t$ under scenario $k(\mathrm{MW})$

the limits of $P_{d, t}^{k}$ (MW)

up-regulated reserve capacity that can be provided by the system at time $t$ under scenario $k$ (MW)

up-regulated reserve capacity that can be provided by thermal power unit $i$ at time $t$ under scenario $k(\mathrm{MW})$

up-regulated reserve capacity that can be provided by gas power unit $j$ at time $t$ under scenario $k(\mathrm{MW})$

up-regulated reserve capacity that can be provided by pumped storage unit at time $t$ under scenario $k(\mathrm{MW})$

down-regulated reserve capacity that can be provided by the system at time $t$ under scenario $k(\mathrm{MW})$

down-regulated reserve capacity that can be provided by thermal power unit $i$ at time $t$ under scenario $k(\mathrm{MW})$

down-regulated reserve capacity that can be provided by gas power unit $j$ at time $t$ under scenario $k$ (MW)

down-regulated reserve capacity that can be provided by pumped storage unit at time $t$ under scenario $k(\mathrm{MW})$

maximum up-climb rates of thermal power unit $i(\mathrm{MW} / \mathrm{min})$

maximum down-climb rates of thermal power unit $i(\mathrm{MW} / \mathrm{min})$

maximum up-climb rates of gas power unit $j(\mathrm{MW} / \mathrm{min})$

maximum down-climb rates of gas power unit $j(\mathrm{MW} / \mathrm{min})$

the minimum running time/shut down time allowed by the gas power unit $j$

start-stop status of gas power unit $j$ at time $t$; equal to 1 if gas power unit $j$ starts-up at time $t$ two working states of PSPS; $U_{i n, t}$ is 1 for pumping state, $U_{o u t, t}$ is 1 for power generation state storage capacity of PSPS at time $t$ under scenario $k$ (WM $\cdot h$ )

minimum storage capacity of PSPS (WM.h) 


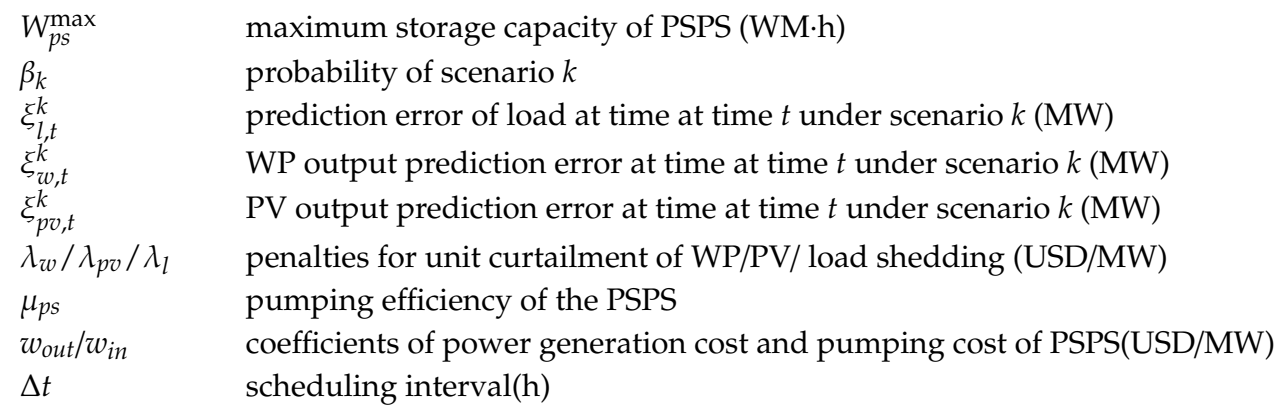

\section{Appendix A}

Table A1. The parameters of units.

\begin{tabular}{|c|c|c|c|c|c|c|c|c|c|c|}
\hline & $\begin{array}{l}\text { Pmax } \\
\text { (MW) }\end{array}$ & $\begin{array}{l}\text { Pmin } \\
\text { (MW) }\end{array}$ & $\begin{array}{c}\mathrm{a} \\
\left(\$ / \mathbf{M W h}^{2}\right)\end{array}$ & $\begin{array}{c}\mathbf{b} \\
(\$ / \mathbf{M W h})\end{array}$ & $\begin{array}{c}c \\
(\$ / h)\end{array}$ & $\begin{array}{c}\mathrm{Ru} \\
(\mathrm{MW} / \mathrm{min})\end{array}$ & $\begin{array}{c}\text { Rd } \\
(\mathrm{MW} / \mathrm{min})\end{array}$ & $\begin{array}{l}\text { On } \\
\text { (\$) }\end{array}$ & $\begin{array}{l}\text { Off } \\
(\$)\end{array}$ & $\begin{array}{c}\mathrm{T} \\
\text { (h) }\end{array}$ \\
\hline 1 & 455 & 150 & 0.00031 & 16.19 & 200 & 2.5 & 2.5 & 20,000 & 20,000 & 12 \\
\hline 2 & 455 & 150 & 0.00031 & 17.26 & 200 & 2.5 & 2.5 & 20,000 & 20,000 & 12 \\
\hline 3 & 300 & 70 & 0.00031 & 16.60 & 300 & 1.2 & 1.2 & 18,000 & 18,000 & 10 \\
\hline 4 & 80 & 20 & 0.00025 & 16.50 & 400 & 1.2 & 1.2 & 15,000 & 15,000 & 8 \\
\hline 5 & 60 & 15 & 0.00511 & 19.70 & 800 & 1.0 & 1.0 & 5000 & 5000 & 1 \\
\hline 6 & 60 & 15 & 0.00712 & 22.26 & 800 & 1.0 & 1.0 & 5000 & 5000 & 2 \\
\hline
\end{tabular}

Table A2. Table of full names and acronyms.

\begin{tabular}{cc}
\hline Full Name & Acronym \\
\hline photovoltaic & PV \\
wind power & WP \\
pumped storage power station & PSPS \\
Latin Hypercube Sampling & LHS \\
Simultaneous Backward Reduction & SBR \\
expected energy not supplied & EENS \\
expected wind power and PV curtailed & EWPPC \\
\hline
\end{tabular}

\section{References}

1. Jamaly, M.; Bosch, J.L.; Kleissl, J.; Zheng, Y.H. Performance Analysis of Power Output of Photovoltaic Systems in San Diego County. In Proceedings of the 2012 IEEE Power and Energy Society General Meeting, San Diego, CA, USA, 22-26 July 2012. [CrossRef]

2. Xue, Y.S.; Lei, X.; Xue, F.; Yu, C.; Dong, C.Y.; Wen, F.S.; Jv, P. A review on impacts of wind power uncertainties on power systems. Proc. CSEE 2014, 34, 5029-5040. [CrossRef]

3. Wu, Y.; Fu, L.; Zhang, S.; Tang, D. Study on a novel co-operated heat and power system for improving energy efficiency and flexibility of cogeneration plants. Appl. Therm. Eng. 2019, 163, 1-13. [CrossRef]

4. Gyalai-Korpos, M.; Zentkó, L.; Hegyfalvi, C.; Detzky, G.; Tildy, P.; Hegedûsné Baranyai, N.; Pintér, G.; Zsiborács, H. The Role of Electricity Balancing and Storage: Developing Input Parameters for the European Calculator for Concept Modeling. Sustainability 2020, 12, 811. [CrossRef]

5. Liu, H.L.; Brown, T.; Andresen, G.B.; Schlachtberger, D.P.; Greiner, M. The role of hydro power, storage and transmission in the decarbonization of the Chinese power system. Appl. Energy 2019, 239, 1308-1321. [CrossRef]

6. Xu, Y.M.; Lang, Y.S.; Wen, B.Y.; Yang, X.N. An Innovative Planning Method for the Optimal Capacity Allocation of a Hybrid Wind-PV-Pumped Storage Power System. Energies 2019, 12, 2809. [CrossRef]

7. Wang, W.X.; Li, C.S.; Liao, X.; Qin, H. Study on unit commitment problem considering pumped storage and renewable energy via a novel binary artificial sheep algorithm. Appl. Energy 2017, 187, 612-626. [CrossRef]

8. Fu, Y.W.; Dong, L.; Hu, W.; Wang, Y.T.; Zhang, J.T.; Wu, S.; Lu, Z.X. Research on joint optimal dispatching method for hybrid power system considering system security. Appl. Energy 2019, 238, 147-163. [CrossRef] 
9. Li, Y.H.; Chen, C.M.; Zhang, J.F. The optimal control strategy for integrated system of wind/photovoltaic/energy storage considering the frequency constraint. In Proceedings of the 2017 Chinese Automation Congress (CAC), Jinan, China, 20-22 October 2017; pp. 6355-6362. [CrossRef]

10. Zhang, L.X.; Zhou, Y.T.; Flynn, D.; Mutale, J.; Mancarella, P. System-level operational and adequacy impact assessment of photovoltaic and distributed energy storage, with consideration of inertial constraints, dynamic reserve and interconnection flexibility. Energies 2017, 10, 989. [CrossRef]

11. Marneris, I.G.; Biskas, P.N.; Bakirtzis, A.G. Stochastic and Deterministic Unit Commitment Considering Uncertainty and Variability Reserves for High Renewable Integration. Energies 2017, 10, 140. [CrossRef]

12. Cheng, J.; Duan, D.; Cheng, X.; Yang, L.; Cui, S. Probabilistic Microgrid Energy Management with Interval Predictions. Energies 2020, 13, 3116. [CrossRef]

13. Nag, S.; Lee, K.Y. Network and Reserve Constrained Economic Analysis of Conventional, Adjustable-Speed and Ternary Pumped-Storage Hydropower. Energies 2020, 13, 4140. [CrossRef]

14. Vázquez Pombo, D.; Iov, F.; Stroe, D.-I. A Novel Control Architecture for Hybrid Power Plants to Provide Coordinated Frequency Reserves. Energies 2019, 12, 919. [CrossRef]

15. Liu, T.; Ye, X.H.; Wu, G.Y.; Su, Z.D.; Zhong, W.Z.; Song, L.X.; Huang, Y.N. An Active Power Control Model of Wind Power Generating Unit Suitable for Medium- and Long-Term Dynamic Simulation of Power Grid. Power Syst. Technol. 2014, 38, 1210-1215. [CrossRef]

16. Chen, J.H.; Wu, W.C.; Zhang, B.M.; Wang, B.; Guo, Q.L. A Spinning Reserve Allocation Method for Power Generation Dispatch Accommodating Large-Scale Wind Power Integration. Energies 2013, 6, 5357. [CrossRef]

17. Zhou, M.; Li, Y.; Li, G.Y. A Day-ahead Power Generation-reserve Bi-level Decision-making Model for Power System Based on Probabilistic Production Simulation. Power Syst. Technol. 2019, 43, 1606-1613. [CrossRef]

18. Yuan, B.; Zhou, M.; Li, G.Y.; Zong, J. A Coordinated Dispatching Model Considering Generation and Operating Reserve for Wind Power Integrated Power System Based on ELNSR. Power Syst. Technol. 2013, 37, 800-807. [CrossRef]

19. Zhou, W.; Peng, Y.; Sun, H.; Wei, Q.H. Dynamic Economic Dispatch in Wind Power Integrated System. Proc. CSEE 2009, 29, 13-18. [CrossRef]

20. Ge, J.; Wang, F.; Zhang, L.Z. Spinning Reserve Model in the Wind Power Integrated Power System. Autom. Electr. Power Syst. 2010, 34, 32-36.

21. Ortega-Vazquez, M.A.; Kirschen, D.S. Optimizing the Spinning Reserve Requirements Using a Cost/Benefit Analysis. IEEE Trans. Power Syst. 2007, 22, 24-33. [CrossRef]

22. Morales, J.M.; Conejo, A.J.; Perez-Ruiz, J. Economic Valuation of Reserves in Power Systems with High Penetration of Wind Power. IEEE Trans. Power Syst. 2009, 24, 900-910. [CrossRef]

23. Bludszuweit, H.; Dominguez-Navarro, J.A.; Llombart, A. Statistical Analysis of Wind Power Forecast Error. IEEE Trans. Power Syst. 2008, 23, 983-991. [CrossRef]

24. Kaplani, E.; Kaplanis, S. A stochastic simulation model for reliable PV system sizing providing for solar radiation fluctuations. Appl. Energy 2012, 97, 970-981. [CrossRef]

25. Sarkar, S.; Ajjarapu, V. MW Resource Assessment Model for a Hybrid Energy Conversion System with Wind and Solar Resources. IEEE Trans. Sustain. Energy 2011, 2, 383-391. [CrossRef]

26. Zou, K.; Agalgaonkar, A.P.; Muttaqi, K.M.; Perera, S. Distribution System Planning With Incorporating DG Reactive Capability and System Uncertainties. IEEE Trans. Sustain. Energy 2012, 3, 112-123. [CrossRef]

27. Rosenblatt, M. Remarks on Some Nonparametric Estimates of a Density Function. Ann. Math. Stat. 1956, 27, 832-837. [CrossRef]

28. Xu, Y.; Hu, Q.R.; Li, F.X. Probabilistic Model of Payment Cost Minimization Considering Wind Power and Its Uncertainty. IEEE Trans. Sustain. Energy 2013, 4, 716-724. [CrossRef]

29. Wu, Y.K.; Su, P.E.; Wu, T.Y.; Hong, J.S. Probabilistic Wind-Power Forecasting Using Weather Ensemble Models. IEEE Trans. Ind. Appl. 2018, 54, 5609-5620. [CrossRef]

30. Liao, G.D.; Ming, J.; Wei, B.Y.; Xiang, H.J.; Jiang, N.; Ai, P.; Dai, C.H.; Xie, X.T.; Li, M.J. Wind Power Prediction Errors Model and Algorithm Based on Non-parametric Kernel Density Estimation. In Proceedings of the 2015 5th International Conference on Electric Utility Deregulation and Restructuring and Power Technologies, Changsha, China, 26-29 November 2015. [CrossRef]

31. Zhou, J.G.; Jia, H.J.; Tian, Z.; Hu, L.L. Short-term wind speed forecasting based on non-parametric kernel density estimation. In Proceedings of the 2012 IEEE Innovative Smart Grid Technologies, Tianjin, China, 21-24 May 2012. [CrossRef] 
32. Qin, Z.L.; Li, W.Y.; Xiong, X.F. Estimating wind speed probability distribution using kernel density method. Electr. Power Syst. Res. 2013, 81, 2139-2146. [CrossRef]

33. Li, R.S.; Wu, B.X.; Li, X.W.; Zhou, F.Q.; Li, Y.B. Design of wind-solar and pumped-storage hybrid power supply system. In Proceedings of the 2010 3rd IEEE International Conference on Computer Science and Information Technology, Chengdu, China, 9-11 July 2010. [CrossRef]

34. Pan, W.X.; Fan, Y.W.; Zhu, L.; Gao, A. The Optimal Sizing for Pumped Storage System in Wind Farm. Trans. China Electrotech. Soc. 2008, 23, 120-124. [CrossRef]

35. Zhao, Y.; Shen, Z.J.; Zhou, N.C.; Zhou, J.Q.; Xu, K.Y. Reliability assessment of bulk power systems utilizing sequential simulation and nonparametric kernel density estimation. Autom. Electr. Power Syst. 2008, 32, 14-19. [CrossRef]

36. EirGrid System Performance Data [DB/OL]. Available online: http://www.eirgrid.com/operations/ systemperformancedata/ (accessed on 12 December 2019).

37. Zhao, S.Q.; Hu, L.N.; Tian, J.F.; Xu, Z.Y. Contract power decomposition model of multi-energy power system based on mid-long term wind power and photovoltaic electricity forecasting. Electr. Power Autom. Equip. 2019, 39, 13-19. [CrossRef]

38. Ai, X.M.; Tayierjiang, B.; Yang, L.B.; Yang, J.H.; Fang, J.K.; Wen, J.Y. Optimizing the Spinning Reserve in Wind Power System Using Scenario Method. Power Syst. Technol. 2018, 42, 835-841. [CrossRef]

39. Chen, Y.; Wen, J.; Cheng, S. Probabilistic Load Flow Method Based on Nataf Transformation and Latin Hypercube Sampling. IEEE Trans. Sustain. Energy 2013, 4, 294-301. [CrossRef]

40. Heitsch, H.; Römisch, W. Scenario reduction algorithms in stochastic programming. Comput. Optimization Appl. 2003, 24, 187-206. [CrossRef]

41. Zakariazadeh, A.; Alinezhad, L.; Jadid, S. Optimum Simultaneous Clearing of Energy and Spinning Reserve Markets with High Penetration of Wind Power. In Proceedings of the 2010 Asia-Pacific Power and Energy Engineering Conference, Chengdu, China, 28-31 March 2010. [CrossRef]

42. Teng, X.B.; Wu, Z.; Huang, J.; He, J.; Liu, M.; Kang, C.Q. Model and Algorithm of Coal-Fired Unit Cyclic Operation Toward Low-Carbon Development. Power Syst. Technol. 2011, 35, 33-39. [CrossRef]

(C) 2020 by the authors. Licensee MDPI, Basel, Switzerland. This article is an open access article distributed under the terms and conditions of the Creative Commons Attribution (CC BY) license (http://creativecommons.org/licenses/by/4.0/). 